Vívian Viegas Lanzarini

\title{
Análise da ocorrência de peritonites e infecções relacionadas ao cateter de diálise peritoneal em pacientes pediátricos em diálise peritoneal crônica
}

Dissertação apresentada à Faculdade de Medicina da Universidade de São Paulo para obtenção do título de Mestre em Ciências

Área de concentração: Pediatria Orientadora: Dra. Vera Hermina Kalika Koch

São Paulo 2007 


\section{DEDICATÓRIA}

Ao meu esposo, Paolo, pelo amor e apoio dedicados ao longo de todos esses anos, pelo incentivo à minha carreira profissional, sempre com generosidade, paciência e muito bom-humor e pelo incentivo e grande ajuda na análise estatística e na preparação desta dissertação.

À minha filha Mariana, tão querida e amada.

Aos meus pais, Egidio e Zuleika, pelo apoio e pelos ensinamentos que possibilitaram todas as minhas conquistas. 


\section{AGRADECIMENTOS}

À minha orientadora, Dra. Vera Koch, pela paciência e atenção dedicadas à orientação dessa dissertação, pela confiança em mim depositada, pelo apoio sempre acolhedor à minha vida profissional e pessoal. Responsável pela minha formação em Nefropediatria, grande mestra e grande pessoa, além do seu conhecimento técnico indiscutível, sempre foi exemplo de humanismo ao lidar com os pacientes.

À minha mãe, Zuleika, grande amiga, companheira e exemplo de força e coragem, sempre generosa e compreensiva, cujo apoio foi fundamental para a concretização desse projeto.

À Dra. Andréia Watanabe, pela colaboração na construção do banco de dados dos pacientes analisados nessa casuística, pelos ensinamentos em diálise pediátrica, pela sua indiscutível competência e espírito de equipe, exemplo de dedicação e humanismo com os pacientes e, principalmente, pela sua amizade.

A todas as assistentes da Equipe de Nefrologia Pediátrica do Instituto da Criança, Dra. Érica Furusawa, Dra. Maria Fujimura, Dra. Maria Helena Vaisbisch e Dra. Benita, pela minha formação acadêmica e pelo apoio pessoal ao longo desses anos, tornando essa jornada de aprendizado mais agradável, e às amigas Luciana Henriques, Thais Cardoso, Flávia Modanez, Cristina Henriques e Simone Vieira, pelo incentivo e apoio pessoal.

Ao Prof. Dr. Cláudio Leone, pelo auxílio na análise estatística.

Ao Sr. Nivaldo Lira Rocha e à Sra. Milene Aparecida Ribeiro Rocha, do setor de xérox do Instituto da Criança, por toda a colaboração na realização de cópias xerográficas e impressão do presente trabalho, sempre com profissionalismo, bom humor e disposição. 
À bibliotecária Mariza Kazue U. Yoshikawa, sempre muito prestativa.

A todos os pacientes que participaram deste estudo, cuja força e coragem para lutar contra as dificuldades me fortalecem para seguir pesquisando e aprimorando meus conhecimentos.

A todos os meus familiares e amigos, pelo suporte emocional e compreensão.

A Deus, agradeço tudo o que recebi nessa vida, inclusive minha vocação profissional, por permitir que eu me tornasse um instrumento seu no cuidado das crianças portadores de doença renal crônica. 
Essa dissertação está de acordo com as seguintes normas, em vigor no momento desta publicação:

Referências: adaptado de International Committee of Medical Journals Editors (Vancouver)

Universidade de São Paulo. Faculdade de Medicina. Serviço de Biblioteca e Documentação. Guia de apresentação de dissertações, teses e monografias. Elaborado por Anneliese Carneiro da Cunha, Maria Julia de A. L. Freddi, Maria F. Crestana, Marinalva de Souza Aragão, Suely Campos Cardoso, Valéria Vilhena. $2^{\mathrm{a}}$ ed. São Paulo: Serviço de Biblioteca e Documentação; 2005.

Abreviaturas dos títulos dos periódicos de acordo com List of Journals Indexed in Index Medicus. 


\section{SUMÁRIO}

Lista de abreviaturas e siglas

Lista de tabelas

Lista de gráficos

Resumo

Summary

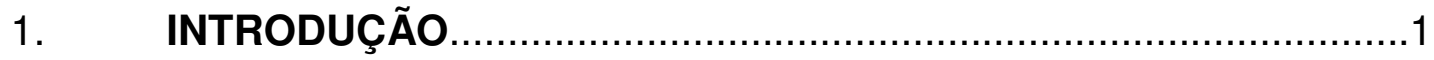

1.1 Aspectos históricos......................................................

1.2 Sobrevida em DP pediátrica e principais causas de mortalidade................................ 3

1.3 Complicações em DP pediátrica......................................5

1.3.1 Complicações não infecciosas relacionadas à DP

1.3.1.1 Complicações mecânicas.

1.3.1.2 Complicações relacionadas

ao cateter de diálise. .8

1.3.1.3 Complicações relacionadas à técnica de DP .9

1.3.2 Morbidade cardiovascular e síndrome "MIA". .11

1.3.3 Desnutrição. .13

1.4 Adequação em diálise peritoneal. 15

1.5 Complicações infecciosas relacionadas à Diálise.

1.5.1 Resposta imunológica no paciente portador de DRC 
1.6 Diálise no Instituto da Criança e

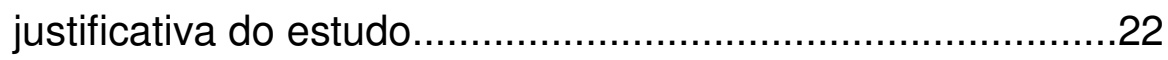

2. OBJETIVOS .26

2.1 Objetivo geral .26

2.2 Objetivos específicos .26

3. MÉTODOS. .29

3.1 Dados obtidos dos prontuários. 29

3.2 Análise estatística .31

3.3 Definições. .33

3.4 Protocolo de tratamento. .34

4. RESULTADOS 37

4.1 Análise de peso e estatura dos pacientes .37

4.2 Análise dos episódios infecciosos. .40 
4.3 Infecções de óstio associadas ou não a infecção do túnel do cateter de diálise (óstio/túnel).

4.3.1 Agentes etiológicos nas infecções

de óstio/túnel do cateter de diálise.

4.3.2 Tratamento das infecções de óstio/túnel do cateter de diálise.

4.3.3 Complicações nas infecções de óstio/túnel do cateter de diálise.

4.3.4 Análise isolada das infecções de túnel do cateter.

4.4 Peritonites

4.4.1 Agentes etiológicos nas peritonites.

4.4.2 Tratamento das peritonites

4.4.2.1 Utilização da técnica de selo de antibiótico no cateter de diálise.

\subsubsection{Complicações relacionadas aos} episódios de peritonite.

4.5 Peritonites associadas a infecções de óstio/túnel do cateter.

4.5.1 Agentes etiológicos nas peritonites associadas a infecções de óstio/túnel do cateter. .55

4.5.2 Tratamento das peritonites associadas a infecções de óstio/túnel do cateter. .56

4.5.3 Complicações nas peritonites associadas a infecções de óstio/túnel do cateter.

4.5.4 Análise do episódio isolado de infecção de túnel do cateter associada a peritonite .59

4.6 Análise das complicações nos 3 grupos de infecção 59 
4.7 Análise dos possíveis fatores de risco para infecção

4.8 Perfil de sensibilidade dos Staphylococcus sp a oxacilina. .65

5. DISCUSSÃO. .68

6. CONCLUSÕES .84

7. REFERÊNCIAS BIBLIOGRÁFICAS. .86 


\section{LISTA DE ABREVIATURAS E SIGLAS}

DP Diálise peritoneal

DPA Diálise peritoneal automatizada

DPAC Diálise peritoneal ambulatorial contínua

DPI Diálise peritoneal intermitente

DRC Doença renal crônica

EDTA "European Dialysis and Transplant Association"

Est/ld Estatura/idade

FMUSP Faculdade de Medicina da Universidade de São Paulo

gram- Gram-negativos

gram+ Gram-positivos

HC Hospital das Clínicas

ICr Instituto da Criança

IMC/Id Índice de massa corpórea/idade

IPPR "International Pediatric Peritonitis Registry"

IQ25-75 Intervalo interquartil 25\%-75\%

KDOQI "Kidney Disease Outcomes Quality Initiative"

MIA "malnutrition, inflammation and atherosclerosis"

NAPRTCS "North American Pediatric Renal Transplant Cooperative Study"

PCR Proteína C reativa

Peso/ld Peso/idade

USRDS "United States Renal Data System" 


\section{LISTA DE TABELAS}

Tabela 1- Dados demográficos dos pacientes relativos a sexo, idade cronológica, em anos, ao início da diálise (mediana, valor máximo e valor mínimo), etiologia da doença renal crônica, destino dos pacientes após diálise peritoneal, seqüência de modalidade de diálise, tempo em diálise, em meses (mediana, valor máximo e valor mínimo).

Tabela 2 - Análise dos episódios infecciosos segundo densidade de incidência de infecção, em episódios/paciente-ano, tipo de aquisição, necessidade de internação, tempo de internação (mediana, intervalo interquartil 25\%-75\% ou IQ25-75), em dias, idade ao diagnóstico (mediana, IQ2575), em meses, e modalidade de diálise ao diagnóstico.

Tabela 3 - Número (№) de agentes isolados nas culturas de secreção de óstio nos 54 episódios de infecção de óstio/túnel do cateter de diálise

Tabela 4 - Agentes etiológicos isolados nas culturas positivas de secreção de óstio nos episódios de infecção de óstio/túnel do cateter de diálise

Tabela 5 - Agentes etiológicos isolados nas culturas de secreção de óstio nos 11 episódios de infecções de óstio/túnel do cateter de diálise de aquisição hospitalar. 
Tabela 6 - Antibioticoterapia inicial empírica nos 54 episódios de infecção de óstio/túnel do cateter de diálise.

Tabela 7 - Agentes etiológicos isolados nas culturas de secreção de óstio nos 5 episódios de infecções de óstio/túnel em que foi necessária a retirada do cateter

Tabela 8 - Agentes etiológicos isolados nas culturas de secreção de óstio nos 14 episódios de infecções de óstio/túnel que evoluíram com colonização do óstio.

Tabela 9 - Complicações nos 23 episódios de infecção de óstio/túnel causados por $S$. aureus 45

Tabela 10 - Complicações nos 7 episódios de infecção de óstio/túnel causados por Pseudomonas aeruginosa

Tabela 11 - Complicações nos 7 episódios de infecção de óstio/túnel causados por Staphylococcus coagulase negativo.. 46

Tabela 12 - Complicações nos 4 episódios de infecção de óstio/túnel causados por Corynebacterium 46

Tabela 13 - Número (№) de agentes isolados nas culturas de líquido peritoneal nos 65 episódios de peritonite

Tabela 14 - Agentes etiológicos isolados nas culturas positivas de líquido peritoneal nos episódios de peritonite 48

Tabela 15 - Agentes etiológicos isolados nas culturas de líquido peritoneal nos 12 episódios de peritonite de aquisição hospitalar .48 
Tabela 16 - Antibioticoterapia inicial empírica nos 65 casos de peritonite

Tabela 17 - Agentes etiológicos envolvidos, antibióticos, doses, tempo de uso e eficácia nos 15 casos de peritonite em que foi utilizado selo de antibiótico no cateter de diálise 51

Tabela 18 - Agentes etiológicos nos 14 episódios de peritonite em que foi necessária a retirada do cateter de diálise 52

Tabela 19 - Agentes etiológicos nos 7 episódios de peritonite em que houve evolução para perda funcional peritoneal 52

Tabela 20 - Complicações nos 15 episódios de peritonite causados por $S$. aureus 53

Tabela 21 - Complicações nos 13 episódios de peritonite causados por Staphylococcus coagulase negativo 53

Tabela 22 - Complicações nos 4 episódios de peritonite causados por Acinetobacter baumanii 54

Tabela 23 - Complicações nos 3 episódios de peritonite causados por Candida sp .54

Tabela 24 - Número (№) de agentes isolados nas culturas dos 13 episódios de peritonites associadas a infecções de óstio/túnel 55

Tabela 25 - Agentes etiológicos isolados nas culturas dos 13 episódios de peritonites associadas a infecções de óstio/túnel 
Tabela 26 - Agentes etiológicos isolados em cada episódio de peritonite associada a infecção de óstio/túnel 56

Tabela 27 - Antibioticoterapia inicial empírica nos 13 casos de peritonite associada a infecção de óstio/túnel do cateter 56

Tabela 28 - Agentes etiológicos nos 3 episódios de peritonites associadas a infecções de óstio/túnel em que foi necessária a retirada do cateter 58

Tabela 29 - Agentes etiológicos nos 2 episódios de peritonites associadas a infecções de óstio/túnel em que houve evolução para perda funcional peritoneal .58

Tabela 30 - Complicações nos 6 episódios de peritonite associada a infecção de óstio/túnel causados por Staphylococcus aureus 58

Tabela 31 - Análise dos fatores de risco em potencial nos pacientes que apresentaram e nos que não apresentaram episódios infecciosos, em relação à idade ao início da diálise, em anos (mediana, IQ 25-75), cirurgia abdominal prévia, diálise peritoneal prévia, presença de vazamentos pelo óstio, presença de derivações abdominais, uso de antibiótico profilático à passagem do cateter, tempo entre passagem do cateter e início da diálise, em dias (mediana e IQ 25-75) e porcentagem de pacientes com nível de albumina sérica $<3,5 \mathrm{~g} / \mathrm{dL}$ .64 
Tabela 32 - Cálculo da densidade de incidência de infecção (episódios/ paciente-mês) em quatro categorias de infecção (óstio/túnel, peritonite, peritonite associada a infecção de óstio/túnel e em todas as peritonites) nas três modalidades de diálise (DPI, DPAC, DPA)

Tabela 33 - Comparação da densidade de incidência de infecção (episódios/ paciente-mês) em quatro categorias de infecção (óstio/túnel, peritonite, peritonite associada a infecção de óstio/túnel e em todas as peritonites), nas 3 modalidades de diálise (DPI, DPAC, DPA), pelo cálculo do escore Z

Tabela 34 - Perfil de sensibilidade dos 68 Staphylococcus $s p$ isolados nas culturas de óstio e de líquido peritoneal 65

Tabela 35 - Perfil de sensibilidade dos 45 Staphylococcus aureus isolados nas culturas de óstio e de líquido peritoneal 65

Tabela 36 - Perfil de sensibilidade dos 23 Staphylococcus coagulase negativo isolados nas culturas de óstio e de líquido peritoneal .66 


\section{LISTA DE GRÁFICOS}

Gráfico 1 - Cálculo do escore Z de estatura/idade (Est/ld z), peso/idade (Peso/ld z), e IMC/idade (IMC/ld z) dos pacientes ao início do programa de diálise peritoneal

Gráfico 2 - Comparação do escore Z de estatura/idade (Z E/I) dos pacientes ao início (i) e ao final (f) do programa de diálise peritoneal

Gráfico 3 - Comparação do escore $Z$ de peso/idade (Z P/l) dos pacientes ao início (i) e ao final (f) do programa de diálise peritoneal

Gráfico 4 - Comparação do escore Z de IMC/idade (Z IMC/id) dos pacientes ao início (i) e ao final (f) do programa de diálise peritoneal 39

Gráfico 5 - Análise dos episódios em que houve perda funcional peritoneal de acordo com os agentes etiológicos, nos casos de peritonite e peritonite associada a infecção de óstio/túnel. Risco de perda funcional peritoneal com intervalo de confiança de $95 \%$ 60

Gráfico 6 - Análise dos episódios em que houve perda funcional peritoneal de acordo com o tipo de agente bacteriano: gram-positivos (gram+) e gram-negativos (gram-). Risco de perda funcional peritoneal com intervalo de confiança de $95 \%$ 
Gráfico 7 - Análise dos episódios em que houve evolução para colonização do óstio de acordo com os agentes etiológicos, nos casos de infecções de óstio e peritonites associadas a infecção de óstio. Risco de colonização com intervalo de confiança de $95 \%$

Gráfico 8 - Análise dos episódios em que houve evolução para colonização do óstio de acordo com o tipo de agente bacteriano: gram-positivos (gram+) e gram-negativos (gram-). Risco de colonização com intervalo de confiança de $95 \%$

Gráfico 9 - Análise dos casos em que houve necessidade de retirada do cateter de acordo com os agentes etiológicos, nos três grupos de infecção. Risco de retirada com intervalo de confiança de $95 \%$ 62

Gráfico 10 - Análise dos casos em que houve necessidade de retirada do cateter de acordo com o tipo de agente bacteriano: gram-positivos (gram+) e gram-negativos (gram-). Risco de retirada com intervalo de confiança de $95 \%$ 62

Gráfico 11 - Análise dos episódios em que houve necessidade de retirada do cateter de acordo com o grupo de infecção. Risco de retirada com intervalo de confiança de $95 \%$ 63

Gráfico 12 - Perfil de sensibilidade à oxacilina dos $S$. aureus e Staphylococcus coagulase negativo (S. coag-) isolados nas culturas de óstio e de líquido peritoneal ao longo do período avaliado (1994-2005) 


\section{RESUMO}

Lanzarini VV. Análise da ocorrência de peritonites e infecções relacionadas ao cateter de diálise peritoneal em pacientes pediátricos em diálise peritoneal crônica [dissertação]. São Paulo: Faculdade de Medicina, Universidade de São Paulo; 2007. 96p.

Introdução: Diálise peritoneal (DP) é a modalidade de diálise mais utilizada em pacientes pediátricos portadores de doença renal crônica (DRC) em todo o mundo. Peritonites e infecções de óstio e túnel do cateter de diálise peritoneal constituem as duas primeiras causas de morbidade e falha de tratamento em pacientes em programa de diálise peritoneal. Objetivo: Caracterizar o perfil dos episódios de peritonites e infecções de óstio e túnel nos pacientes em programa de diálise peritoneal crônica na Unidade de Nefrologia Pediátrica do Instituto da Criança do HC FMUSP. Métodos: Avaliou-se o período compreendido entre janeiro de 1994, quando foi iniciado o programa de diálise peritoneal crônica nessa unidade, e dezembro de 2005. Foram incluídos todos os pacientes que estiveram em programa de diálise peritoneal crônica no período, cujos prontuários estivessem acessíveis para análise. Realizou-se revisão dos prontuários quanto aos dados demográficos dos pacientes, peso e estatura ao início e ao final do programa de diálise, etiologia e evolução clinica de cada episódio infeccioso, e presença de fatores de risco para peritonites e infecções relacionadas ao cateter de DP. Realizou-se análise descritiva dos dados gerais, cálculo da 
incidência de episódios infecciosos no período estudado e freqüência de fatores de risco para infecção. Analisaram-se descritivamente os perfis de todos os episódios infecciosos. Resultados: Cinqüenta e três pacientes foram estudados, sendo $32(60,4 \%)$ do sexo masculino, com mediana de idade de 9,5 (0,3 a 18,2) anos. A etiologia da DRC foi má-formação urológica em $32(60,4 \%)$ pacientes, glomerulopatias em 15 (28,3\%), tubulopatias em 4 (7,5\%) e outras causas em 2 (3,8\%). A mediana do tempo em diálise foi de 20,5 (3,9 a 87,1) meses. Houve 132 episódios infecciosos no período observado, em 42 (79\%) pacientes, sendo 65 peritonites, 54 infecções de óstio e túnel e 13 infecções de óstio e túnel associadas a peritonite, num total de 1329,3 paciente-mês. Assim sendo, houve 0,49 infecções de óstio e túnel/ paciente-ano, 0,59 peritonites/ paciente-ano e 0,12 infecções de óstio e túnel associadas a peritonite/ paciente-ano. Os agentes mais encontrados nas infecções de óstio e túnel foram S. aureus, isolado em 23 culturas (43\% das culturas de óstio positivas), Staphylococcus coagulase negativo em 7 (13\%) e Pseudomonas aeruginosa em 7 (13\%). Nas peritonites, os agentes mais encontrados foram S. aureus, isolado em 15 culturas (27\% das culturas de líquido peritoneal positivas), Staphylococcus coagulase negativo em 13 (24\%) e Acinetobacter baumanii em 4 (7\%). Nos casos de peritonite associada a infecção de óstio e túnel, S. aureus foi isolado em 6 culturas (67\% das culturas de secreção de óstio) e Staphylococcus coagulase negativo em 2 (22\%). Staphylococcus sp, Pseudomonas aeruginosa e fungos foram os agentes mais relacionados a complicações como colonização do óstio, evolução para peritonite, necessidade de troca do 
cateter e perda funcional peritoneal. Devido ao reduzido número de pacientes que não apresentaram infecções, não foi possível identificar fatores de risco na casuística estudada. Conclusões: As taxas encontradas de peritonites e infecções de óstio e túnel são elevadas. Staphylococcus sp foram os agentes mais encontrados e um dos mais relacionados a complicações. Medidas profiláticas no sentido de diminuir a contaminação por esse agente podem constituir uma intervenção eficaz para a redução das taxas de infecção diálise-relacionadas.

Descritores: Falência renal crônica - Diálise peritoneal - Infecção Peritonite- Pediatria - Staphylococcus. 


\section{SUMMARY}

Lanzarini VV. Peritonitis and catheter related infections in children undergoing chronic peritoneal dialysis [dissertation]. São Paulo: Faculdade de Medicina, Universidade de São Paulo; 2007. 96p.

Introduction: Peritoneal dialysis (PD) is one of the most frequently used modality of chronic dialysis in children presenting with end stage renal disease (ESRD) worldwide. Peritonitis and exit site and/or tunnel infections $(\mathrm{ESI} / \mathrm{TI})$ are the major causes of morbidity and treatment failure in patients undergoing peritoneal dialysis. Objective: To study the episodes of peritonitis and $\mathrm{ESI} / \mathrm{TI}$ in patients undergoing maintenance peritoneal dialysis in the Pediatric Nephrology Unit of Instituto da Criança - HC FMUSP. Methods: All patients whose files were available for analysis were included. Data was collected from January 1994, at the beginning of the program of chronic peritoneal dialysis in this unit, until December 2005. Demographic data, weight and height at the start and at the end of the period of study, etiology and clinical outcome of each infectious episode and risk factors for peritonitis and catheter related infections, were analyzed. Descriptive analysis of demographic data was performed. Incidence rates of peritonitis and $\mathrm{ESI} / \mathrm{TI}$ and frequency of possible risk factors rates were calculated. Results: Fifty three patients were studied, 32 (60.4\%) male, with median age of 9.5 ( 0.3 to 18.2 ) years. Primary renal disease was urological malformation in $32(60.4 \%)$ patients, glomerular diseases in $15(28.3 \%)$, tubular diseases 
in $4(7.5 \%)$ and other causes in $2(3.8 \%)$. Median time on dialysis was 20.5 (3.9 a 87.1) months. In 1329.3 patient-month, 132 episodes of peritonitis and/or ESI/TI occurred in 42 (79\%) patients, including 54 episodes of ESI/TI, 65 episodes of peritonitis and 13 episodes of peritonitis associated with $\mathrm{ESI} / \mathrm{TI}$, yielding an annualized rate of $0.49,0.59$ and 0.12 episodes/patientyear, respectively. The most frequent etiologic agents in the ESI/TI group were S. aureus, isolated in 23 exit site cultures (43\% of positive cultures), Staphylococcus coagulase negative in 7 (13\%) and Pseudomonas aeruginosa in $7(13 \%)$. In the peritonitis group, the most frequent agents were S. aureus, isolated in 15 peritoneal fluid cultures $(27 \%$ of positive cultures), Staphylococcus coagulase negative in 13 (24\%) and Acinetobacter baumanii in $4(7 \%)$. In the episodes of peritonitis associated with $\mathrm{ESI} / \mathrm{TI}, \mathrm{S}$. aureus was isolated in $6(67 \%)$ exit site cultures and Staphylococcus coagulase negative in 2 (22\%). Complications such as exit site colonization, evolution to peritonitis, catheter removal and peritoneal failure were mostly associated with Staphylococcus sp, Pseudomonas aeruginosa and fungi infections. No risk factors could be identified due to the reduced number of patients not affected by infections. Conclusion: Peritonitis and $\mathrm{ESI} / \mathrm{TI}$ rates in this population were high. Staphylococcus $s p$ was the most frequently recovered agent. Infections caused by this agent presented a high rate of complications. Prophylactic measures to decrease contamination with this microorganism could be an efficient intervention to reduce dialysis associated infection rates. 
Descriptors: Kidney failure, chronic - Peritoneal dialysis - Infection Peritonitis- Pediatrics - Staphylococcus. 


\section{Introdução}




\section{INTRODUCÃO}

\subsection{ASPECTOS HISTÓRICOS}

Diálise peritoneal (DP) é a modalidade de diálise mais utilizada em pacientes pediátricos portadores de doença renal crônica (DRC) em todo o mundo.

Desde o século passado já se sabia que o peritônio possui características de membrana semipermeável, e chegou a ser utilizado para a administração de líquidos. Em 1918, Blackfan e Maxcy descreveram o uso, com sucesso, de infusões intraperitoneais de solução salina em crianças desidratadas (Blackfan et al., 1918).

Em 1923, Georg Ganter descreveu o primeiro uso clínico da cavidade peritoneal com o intuito de promover depuração de solutos, ou seja, a realização de diálise peritoneal. Entretanto, somente em 1949 Swan e Gordon realizaram a primeira diálise peritoneal em crianças com insuficiência renal aguda. $\mathrm{Na}$ década de 60 , crianças e lactentes com insuficiência renal aguda passaram a ser tratadas com diálise peritoneal intermitente (DPI). O sucesso da técnica adaptada, conhecida desde então como DPI aguda, foi primeiramente relatado por Segar, em 1961, e, por Ettelford, em 1962 (Abensur et al., 2006).

Um cateter de longa permanência foi desenvolvido por Palmer, em 1964, e aperfeiçoado por Tenckhoff e Schecter, permitindo a realização da DP por períodos mais prolongados e evitando as punções abdominais repetidas, utilizadas até então. Também naquela década surgiram as 
primeiras máquinas para diálise peritoneal automática viabilizando a utilização desta modalidade de diálise como terapia de substituição renal no paciente crônico (Abensur et al., 2006). Em 1976, Popovich e Moncrief descreveram um método contínuo de diálise peritoneal em adultos (Popovich et al., 1976), posteriormente denominado diálise peritoneal ambulatorial contínua (DPAC). Em 1978, em Toronto, Canadá, empregou-se pela primeira vez o método de DPAC em uma criança (Balfe et al., 1981). Logo essa técnica passou a ser utilizada em muitos centros americanos e europeus. Com o advento de máquinas cicladoras, a diálise peritoneal automatizada foi progressivamente se popularizando em todo o mundo (Schärer et al., 2004).

Novos sistemas de conexão e desconexão foram criados, com o intuito de diminuir a manipulação pelo paciente e o risco de contaminação, com queda significativa da incidência de peritonites ao longo do tempo. As cicladoras de DP foram modernizadas, tornando a diálise peritoneal automatizada (DPA) a modalidade de terapia de substituição renal mais empregada na faixa etária pediátrica atualmente (Abensur et al., 2006).

\subsection{SOBREVIDA EM DP PEDIÁTRICA E PRINCIPAIS CAUSAS DE}

\section{MORTALIDADE}

As principais fontes de dados demográficos em pacientes pediátricos em diálise citadas na literatura são: EDTA ("European Dialysis and Transplant Association"), NAPRTCS ("North American Pediatric Renal Transplant Cooperative Study”), USRDS (“United States Renal Data 
System”), o Registro Japonês (“Japanese National Registry”) e o Registro Italiano ("Italian Registry of Pediatric Chronic Peritoneal Dialysis").

Segundo o relatório do NAPRTCS de 2001, a sobrevida em 1, 2 e 3 anos dos pacientes pediátricos em diálise foi de 95\%, 90,1\% e 85,7\%, respectivamente. Este relatório analisou, entre os anos de 1992 a 2000, os dados de 2221 pacientes pediátricos em diálise, com idade entre zero a 21 anos. As maiores taxas de mortalidade referem-se ao grupo de crianças que iniciaram diálise com menos de 1 ano de idade. Neste subgrupo, a sobrevida em 1, 2 e 3 anos foi de $84,5 \%, 74,4 \%$ e $68,2 \%$, respectivamente. A principal causa de morte em diálise, nesta casuística, foi infecção (24\%) e a segunda causa, eventos cardiopulmonares (21\%) (Neu et al., 2001).

Segundo dados do USRDS, entre os anos de 1991 e 1997, a taxa de mortalidade anual para pacientes pediátricos (0 a 19 anos) em diálise foi de 3,6\%. Nesta casuística, foi observada maior mortalidade no grupo de crianças que iniciaram diálise com menos de 2 anos de idade (Wolfe et al., 1999; Wong et al., 2002).

A análise dos dados de 458 pacientes do Registro Italiano revela taxa de sobrevida de 97,1\%, 93,4\% e 90,5\% em 12, 36 e 60 meses, respectivamente. Nesta casuística, complicações cardiovasculares foram a principal causa de morte, em $60 \%$ dos casos. Infecção foi uma causa de morte menos freqüente do que na maioria das outras séries. A idade precoce ao início da diálise confirmou-se como fator preditor para mortalidade (Verrina et al., 2004). 
É importante destacar que, em geral, nessas casuísticas, são incluídas várias categorias no grupo de complicações cardiovasculares, como arritmias, infarto agudo do miocárdio, miocardiopatia, doenças valvulares, entre outros, o que pode ser um fator de confusão. Por exemplo, o diagnóstico de arritmia pode ser secundário a hipercalemia, que refletiria acidose ou má aderência à dieta, e não um evento cardiovascular propriamente dito (Querfeld, 2004).

\subsection{COMPLICAC̣ÕES EM DP PEDIÁTRICA}

As complicações em DP podem ser classificadas, didaticamente, em complicações não infecciosas e infecciosas.

\subsubsection{COMPLICAC̄ÕES NÃO INFECCIOSAS RELACIONADAS À DP}

As complicações não infecciosas relacionadas à diálise são menos comuns que as infecciosas, mas são relativamente freqüentes e muitas vezes levam à falência do método. Elas podem ser classificadas em: A) complicações mecânicas; B) relacionadas ao cateter; C) relacionadas à técnica do procedimento (Harvey, 2004).

\subsubsection{COMPLICACÕES MECÂNICAS}

As principais complicações mecânicas são: hérnias, vazamentos, hidrotórax, hemoperitônio e dor abdominal.

As hérnias são complicações comuns em crianças em diálise peritoneal, com uma freqüência relatada de 11,8 a $53 \%$ (von Lilien et al., 
1987; Holtta et al., 1997). Podem ser inguinais, umbilicais ou incisionais. Elas ocorrem predominantemente devido ao aumento da pressão intraperitoneal após infusão do líquido na cavidade peritoneal. A sua incidência é inversamente proporcional à idade, sendo maior no primeiro ano de vida. Outros fatores relacionados ao seu aparecimento são: o volume de infusão do dialisato, velocidade de incremento do volume de infusão na prescrição dialítica, a modalidade de DP e a susceptibilidade individual do paciente. Freqüentemente, as hérnias requerem correção cirúrgica (Harvey, 2004).

Vazamentos, também ocasionados predominantemente pelo aumento da pressão intraperitoneal, podem ser caracterizados como recentes, ocorrendo nos primeiros 30 dias após implantação do cateter de diálise, ou tardios. Os vazamentos recentes geralmente ocorrem pelo óstio do cateter. Os vazamentos mais tardios geralmente são intra-abdominais, freqüentemente associados ao aparecimento de hérnias, e podem se apresentar como edema de parede abdominal e/ou genital. Resolução espontânea dos vazamentos pode ocorrer com medidas para reduzir a pressão intraperitoneal, como redução do volume de infusão. A interrupção temporária do procedimento dialítico pode ser necessária para a resolução do vazamento. Neste caso, a transferência temporária para hemodiálise pode ser uma opção para pacientes com função renal residual muita baixa. Vazamentos tardios geralmente requerem revisão cirúrgica do cateter (Harvey, 2004). 
Hidrotórax é uma complicação incomum, mas potencialmente grave. Sua incidência é de $2 \%$ (Stone et al., 1986). Pode também ser conseqüente ao aumento da pressão intraperitoneal e ocorre entre duas a quatro semanas após início da diálise, em $40-50 \%$ dos casos. Pode aparecer de maneira insidiosa, com pequenos acúmulos de líquido peritoneal, ou de forma dramática, como dispnéia de origem aguda, caracterizada por ultrafiltração inadequada na ausência de sinais de hipervolemia. Geralmente é unilateral, ocorrendo com maior freqüência à direita. Em muitos pacientes, há uma fragilidade diafragmática pleural-peritoneal predispondo à sua ocorrência. Em alguns casos, não se caracteriza esse defeito de comunicação, sendo sua etiologia explicada por comunicação linfática subdiafragmática. Pode haver resolução do hidrotórax após redução do volume de infusão ou com interrupção temporária da DP. Em casos recorrentes, a etiologia do hidrotórax pode estar relacionada à presença de defeitos diafragmáticos podendo ser necessária realização de reparos cirúrgicos ou pleurodese. Esta complicação pode, algumas vezes, levar à falência do método, sendo necessária transferência para hemodiálise (Harvey, 2004).

Hemoperitônio é uma complicação mais comum em mulheres em idade reprodutiva, associado aos ciclos menstruais, mas também pode ocorrer em pacientes em idade não reprodutiva. Pode ser secundário a trauma, atividade física, distúrbio da coagulação, pancreatite, coleciste, úlcera gástrica, ruptura de cistos hepáticos ou renais, sangramento retroperitoneal, infecção por citomegalovírus e tumores abdominais. Em 
crianças, a causa mais comum é trauma abdominal ou do cateter. Há também a descrição de hemoperitônio recorrente devido a calcificações peritoneais (Warady et al., 1994). Seu tratamento varia conforme a gravidade e a causa, mas o tratamento convencional inclui administração de heparina na solução de diálise, para prevenir obstrução do cateter pelos coágulos. Banhos de diálise frios, para induzir vasoconstrição, podem ser utilizados (Harvey, 2004).

Dor abdominal é uma complicação pouco freqüente na ausência de peritonite. Geralmente ela ocorre durante a infusão do líquido de diálise ou no final da sua drenagem. $\mathrm{O} \mathrm{pH}$ ácido, temperaturas mais baixas do líquido de diálise ou trauma mecânico, associado à posição do cateter na cavidade peritoneal, são fatores que podem contribuir para o surgimento de dor abdominal (Harvey, 2004).

\subsubsection{COMPLICACÕ̃ES RELACIONADAS AO CATETER DE DIÁLISE}

As complicações não infecciosas relacionadas ao cateter de diálise peritoneal mais comuns são: obstrução, migração na cavidade peritoneal e extrusão do "cuff".

Obstrução do cateter geralmente é causada por omento, adesões mesentéricas ou de outras estruturas intra-abdominais. Pode ser minimizada pela realização de omentectomia parcial à implantação do cateter de diálise. Essa é uma condição que pode requerer revisão cirúrgica laparoscópica do cateter (Brandt et al., 2004). 
Migração do cateter na cavidade peritoneal ocorre em 5 a 10\% dos cateteres (Brandt et al., 2004). É mais comum em crianças, por apresentarem pélvis e abdômen proporcionalmente mais curtos. Essa condição pode ser precipitada por obstipação intestinal ou distensão vesical excessiva. Nesses casos, realização de enema e sondagem vesical podem solucionar o problema. Revisão laparoscópica do cateter pode ser necessária se essas medidas não forem eficazes (Fukui et al., 1999).

A extrusão do "cuff" pode ocorrer quando o "cuff" é posicionado muito próximo ao óstio ou na vigência de infecção do óstio. Se o cateter possui dois "cuffs" e não há evidência de vazamentos, pode-se tentar continuar a utilização do mesmo cateter após "raspagem" do "cuff" extruso. Na maioria das vezes, entretanto, a extrusão parcial do "cuff" leva a irritação e infeção do óstio, fazendo-se necessária a troca do cateter (Brandt et al., 2004).

\subsubsection{COMPLICAC̣ÕES RELACIONADAS À TÉCNICA DE DP}

Complicações relacionadas à técnica de DP incluem calcificações peritoneais e a esclerose peritoneal.

Calcificações peritoneais apresentam-se clinicamente como dor abdominal, hemoperitônio e redução de ultrafiltração. Podem ocorrer mesmo na ausência de calcifilaxia sistêmica e levar à falência peritoneal. Os fatores de risco para seu desenvolvimento são peritonites recorrentes, aumento do produto cálcio $\mathrm{x}$ fósforo e hiperparatireoidismo secundário. Medidas terapêuticas incluem uso de soluções com cálcio baixo e controle do hiperparatireoidismo (Harvey, 2004). 
A esclerose peritoneal e falha de ultrafiltração estão associados ao uso de soluções pouco biocompatíveis de DP e a episódios de peritonites de repetição.

Historicamente, os tratamentos pioneiros em diálise peritoneal foram realizados com soluções para uso endovenoso, como soro fisiológico, soluções de dextrose e Ringer lactato. Nos anos 40, soluções de diálise peritoneal experimentais eram ajustadas de forma a corrigir a composição eletrolítica e corporal; lactato ou acetato eram acrescentados para a correção da acidose metabólica associada à insuficiência renal crônica. Para a remoção do excesso de água, utilizavam-se soluções hipertônicas em relação ao plasma. Dentre os agentes osmóticos empregados na época, a glicose foi considerada o agente mais efetivo e seguro. Frascos de vidro foram substituídos por bolsas plásticas, que também passaram a ter volumes mais adequados para a faixa pediátrica (Maxwell et al., 1995).

As soluções de DP utilizadas nos primórdios da diálise peritoneal não diferem muito das atuais. As soluções de diálise à base de glicose como agente osmótico, de uso rotineiro, são pouco biocompatíveis. Elas apresentam $\mathrm{pH}$ baixo, osmolaridade elevada, altas concentrações de lactato e glicose, além de produtos derivados da degradação da glicose formados no processo de esterilização, causando efeitos deletérios à membrana peritoneal (Imholz et al., 1994; Millar et al., 1998). A exposição contínua do peritônio a esses fatores leva ao comprometimento progressivo da permeabilidade peritoneal por deposição de produtos da glicosilação avançada da glicose no tecido peritoneal (Nakayama et al., 1997). Soluções 
mais biocompatíveis têm sido pesquisadas para minimizar as agressões ao peritônio, dentre estas:

- Soluções contendo aminoácidos, desenvolvidas para repor as perdas de aminoácidos e proteínas que ocorrem durante a diálise peritoneal, melhorando o balanço nitrogenado, principalmente em pacientes desnutridos.

- Soluções contendo icodextrina, um polímero de moléculas de glicose produzida a partir da hidrólise do amido, com capacidade de ultrafiltração prolongada e melhor perfil de biocompatibilidade.

- Soluções com bicarbonato, em substituição às soluções de lactato, potencialmente mais biocompatíveis por ser o bicarbonato mais fisiológico para a membrana peritoneal (Abensur et al., 2006).

Deve-se ressaltar que a reação peritoneal ao contato com soluções pouco biocompatíveis pode diminuir a dialisância da membrana peritoneal, levando a hipervolemia e hipertensão arterial e complicações cardiovasculares. Simultaneamente, a agressão peritoneal pelo uso de soluções pouco biocompatíveis pode exacerbar o estado de inflamação sistêmica e contribuir para o processo de desnutrição e aterosclerose, que caracterizam a síndrome "MIA" ("malnutrition", "inflammation", "atherosclerosis").

\subsubsection{MORBIDADE CARDIOVASCULAR E SÍNDROME "MIA"}

Com os avanços nos cuidados de pacientes portadores de DRC e nas terapias de substituição renal, há aumento na sobrevida de tais pacientes e, 
conseqüentemente, aumento do número de pacientes pediátricos mantidos por períodos cada vez maiores em diálise (Offner et al., 1999; Goodman et al., 2000). Como já foi previamente citada, a mortalidade por doenças cardiovasculares tem aumentado na infância e em adultos jovens, aparecendo como a primeira causa de mortalidade nessa população em algumas casuísticas (Verrina et al., 2004).

Sabe-se que crianças portadoras de DRC em diálise apresentam risco aumentado para doenças cardiovasculares. Há vários fatores de risco para doenças cardiovasculares relacionados à diálise: hipervolemia, hipertensão arterial, dislipidemia, aumento da resistência periférica a insulina e fatores relacionados à uremia, tais como stress oxidativo, elevação do produto cálcio x fósforo, miocardiopatia e inflamação (Querfeld, 2004).

Marcadores sistêmicos de inflamação, como a proteína C reativa (PCR), têm sido descritos, em adultos portadores de DRC, como fatores de risco para a elevada morbi-mortalidade dessa população. Recentemente, tem sido descrita uma forte associação entre inflamação, desnutrição e aterosclerose em adultos renais crônicos, sugerindo a presença de uma síndrome relacionada à elevada mortalidade cardiovascular, denominada síndrome "MIA" (desnutrição, inflamação e aterosclerose) (Stenvinkel et al., 1999). Há poucos estudos que abordam este tema na criança com DRC, mas há evidencias que apontam para a existência desta entidade clínica também na faixa etária pediátrica (Sylvestre et al., 2007).

Em adultos, a mortalidade cardiovascular é 10 a 20 vezes maior em pacientes com DRC terminal do que na população em geral. Os fatores de 
risco tradicionais para doença cardiovascular, tais como dislipidemia, hipertrofia de ventrículo esquerdo, diabetes mellitus, hipertensão arterial e tabagismo, não explicam isoladamente esse aumento na mortalidade. Outros fatores como stress oxidativo, disfunção endotelial e inflamação parecem ter um impacto maior na mortalidade cardiovascular nessa população. Nos últimos anos, inflamação tem sido identificada como fator primordial na gênese de aterosclerose tanto na população geral como em pacientes portadores de DRC (Pecoits-Filho et al., 2002).

Hipervolemia também está associada à inflamação. Em pacientes portadores de insuficiência cardíaca congestiva, pode ser observada desnutrição (caquexia cardíaca) e aumento dos níveis de citocinas próinflamatórias, como TNF-a. Em pacientes renais crônicos ao início da diálise, foi identificada relação entre níveis plasmáticos de IL-6 e massa de ventrículo esquerdo (Pecoits-Filho et al., 2002).

\subsubsection{DESNUTRIC̣ÃO}

Crianças portadoras de DRC podem apresentar graus variados de desnutrição, mesmo antes do início da diálise crônica. Sabe-se que o estado nutricional se correlaciona com mortalidade. Wong et al. (2002) demonstraram, em uma população pediátrica norte-americana, que o decréscimo da albumina sérica em $1 \mathrm{~g} / \mathrm{dL}$ estava associado a um risco de morte $54 \%$ maior, sendo o risco relativo ajustado de 1,54 .

Vários fatores contribuem para a desnutrição na criança renal crônica, como diminuição da ingestão alimentar secundária a anorexia e restrições 
alimentares, e à perda de nutrientes, principalmente pelo processo dialítico. Dentre as causas de anorexia no paciente urêmico podemos citar: alterações do paladar, depressão, restrições dietéticas, dispepsia pela administração de várias medicações, sensação de plenitude gástrica, causada tanto pelo aumento da pressão abdominal relacionado à presença do dialisato na cavidade peritoneal como pela exposição contínua a níveis elevados de glicemia durante a realização da diálise peritoneal com soluções contendo glicose em sua composição. A perda de nutrientes pode ocorrer por proteinúria, e pela perda de albumina pelo peritônio durante a realização da diálise peritoneal (Secker, 2004).

Como não há consenso baseado em evidências sobre a definição de desnutrição no paciente pediátrico com DRC, foram criadas diretrizes baseadas predominantemente em séries de casos e opiniões de especialistas, como parte do projeto "Kidney Disease Outcome Quality Initiatives" (KDOQI). Segundo as recomendações do KDOQI pediátrico, os pacientes em diálise devem ser avaliados do ponto de vista nutricional segundo os seguintes parâmetros: recordatório alimentar de três dias, dosagem de albumina e bicarbonato no sangue, medida de peso e estatura, estimativa do peso seco, medida da prega cutânea do tríceps, medida da circunferência muscular do braço, medida do perímetro cefálico (em crianças menores de três anos de idade), cálculo do escore $Z$ de estatura e do índice peso/estatura. Essas medidas devem ser realizadas, rotineiramente, com intervalo mínimo de um mês para crianças com menos de 2 anos de idade (exceto área de circunferência muscular do antebraço, que pode ser 
realizada a cada 3 a 4 meses). Para crianças acima de 2 anos de idade, essas medidas devem ser realizadas minimamente a cada 3 a 4 meses (exceto albumina e bicarbonato séricos, que devem ser realizados mensalmente). Recomenda-se que o bicarbonato sérico seja mantido acima de $22 \mathrm{mmol} / \mathrm{L}$. Essas medidas devem ser realizadas com intervalos menores em crianças desnutridas ou consideradas de risco para desnutrição, podendo também ser realizadas mais amiúde em crianças com bom ganho pondero - estatural (K DOQI, 2000).

A melhora nutricional das crianças portadoras de DRC, associada ao controle dos demais fatores de risco já citados e ao aperfeiçoamento da qualidade da diálise oferecida, são potencialmente importantes para redução de mortalidade dessas crianças.

\subsection{ADEQUAÇÃO EM DIÁLISE PERITONEAL}

O termo adequação originou-se em estudos de hemodiálise em adultos e tem sido utilizado para se referir à dose de diálise oferecida. Foram desenvolvidas diretrizes pelo KDOQI ("Kidney Disease Outcome Quality Initiatives") quanto à mínima dose de diálise que deveria ser oferecida para pacientes adultos e pediátricos em diálise peritoneal (KDOQI, 1997).

Ainda é controverso qual seria o melhor parâmetro para medir a adequação. A dose de diálise oferecida é obviamente importante, mas adequação envolve também outros parâmetros. A experiência clínica até o momento sugere que o paciente pode ser adequadamente tratado pela diálise peritoneal desde que uma dose minimamente razoável de diálise seja 
oferecida, associada ao controle eficaz da hipervolemia e da pressão arterial e boa nutrição (Diaz-Buxo, 2005).

O índice mais utilizado para medir a dose de diálise é o Kt/V semanal de uréia. $\mathrm{O} \mathrm{Kt} / \mathrm{V}$ é obtido pela divisão da depuração de uréia de 24 horas (renal somada à peritoneal) pelo volume de distribuição de uréia, o qual corresponde ao conteúdo total de água no organismo e é estimado pela equação de Mellitis-Cheek, que varia de acordo com estatura, peso e o sexo da criança. Esse valor é multiplicado por 7 e expresso como Kt/V semanal de uréia (KDOQI, 1997). Segundo as recomendações para diálise do KDOQI de 2006, a mínima dose de diálise oferecida para crianças em diálise peritoneal deveria corresponder a um $\mathrm{Kt} / \mathrm{V}$ semanal de uréia de pelo menos 1,7, avaliado dentro do primeiro mês após o início da diálise e, posteriormente, a cada 4 meses (KDOQI, 2006).

O estudo ADEMEX, no entanto, chamou a atenção para o conceito de que a adequação de diálise, baseada apenas em dados de depuração de soluto, não seria um forte preditor de mortalidade, apontando para a necessidade de critérios mais amplos de adequação (Paniagua et al., 2002). A concentração sérica de albumina, por exemplo, refletindo o estado nutricional do paciente, tem se mostrado um poderoso preditor de mortalidade em diálise peritoneal. Assim sendo, o ajuste da prescrição de diálise deve levar em conta o Kt/V semanal de uréia associadamente a outros parâmetros periodicamente avaliados, como presença ou ausência de sintomas de uremia, correção da anemia, adequação nutricional, controle da 
hipoalbuminemia, controle da pressão arterial e manutenção de euvolemia (Abensur et al., 2006; KDOQI, 2006).

\subsection{COMPLICAC̣̃̃ES INFECCIOSAS RELACIONADAS À DIÁLISE}

Peritonites e infecções relacionadas ao cateter de diálise peritoneal (infecção de óstio e túnel do cateter) constituem as duas primeiras causas de morbidade e falha de tratamento em pacientes em programa de diálise peritoneal, sendo as causas mais comuns de retirada de cateter, transferência de pacientes para a hemodiálise e uso de antibióticos (Furth et al., 2000).

Os principais fatores de risco para o desenvolvimento de peritonites e infecções relacionadas ao cateter de diálise na população pediátrica são: idade do paciente, características do cateter (número de "cuffs" e orientação de saída do óstio), modalidade de diálise (diálise automatizada $\mathrm{x}$ diálise manual) e treinamento do paciente. Outros fatores também citados são: uso de antibiótico profilático à passagem do cateter, presença de derivações abdominais (gastrostomia, vesicostomia e ureterostomia), baixa função renal residual, hipoalbuminemia, realização de diálise peritoneal prévia à entrada no programa de diálise, cirurgia abdominal prévia, vazamentos pelo óstio e uso precoce do cateter de diálise após implante (Gokal et al., 1998; Furth et al., 2000; Rahim et al., 2004; Warady et al., 2004; Boehm et al., 2005).

A idade do paciente tem correlação inversa com as taxas de peritonites e infecções relacionadas a cateter de DP. As crianças menores 
de 2 a 3 anos são as mais acometidas por essa infecções (Rahim et al., 2004; Warady et al., 2004; Boehm et al., 2005).

As características do cateter mais relacionadas a peritonites e infecções de óstio e túnel são o número de "cuffs" e orientação da saída do óstio. O uso de cateteres com "cuff" único está mais associado a infecções do que cateteres com duplo "cuff". Quando o cateter com "cuff" duplo é implantado, um dos "cuffs" é posicionado no subcutâneo, logo abaixo da saída do óstio, e o outro, na camada muscular da parede abdominal, o que faz com que o cateter fique mais bem ancorado, prevenindo trauma local e diminuindo os riscos de contaminação. Orientação superior do óstio está mais associada a infecções, pelo aumento da chance de contaminação do óstio por deposição de suor e detritos. Assim sendo, do ponto de vista de prevenção de infecções, recomenda-se o uso de cateter de DP com duplo "cuff" e com óstio direcionado no sentido crânio-caudal (Furth et al., 2000; Warady et al., 2004).

Quanto à modalidade de diálise, há dados na literatura que sugerem um pequeno decréscimo das taxas de infecção de pacientes em DPA quando comparados com DPAC (Edefonti et al., 1996; NAPRTCS, 2003).

A incidência de perionites e infecções relacionadas a cateter de DP vem diminuindo nos últimos anos graças a melhores cuidados com a colocação e uso dos cateteres de diálise peritoneal, treinamento contínuo do paciente e dos familiares e, sobretudo, com o desenvolvimento de sistemas que minimizam o contato e a contaminação do líquido de diálise peritoneal (Vas, 2002; Piraino, 2004; Warady et al., 2004). 
Enquanto as taxas de peritonite em muitos centros de diálise peritoneal de adultos atingiram um valor ao redor de 0,5 episódios/ pacienteano, ainda se observam elevadas taxas em vários centros pediátricos (Warady et al., 2004).

Segundo o último relato do NAPRTCS, em 2006, a taxa de peritonite nessa população foi de $0,71 /$ paciente-ano ou 1 episódio a cada 17 pacientemês, no ano de 2006 (NAPRTCS, 2006). Essa taxa também vem decaindo ao longo dos anos nessa população. Segundo o relato de 2003, essa taxa era de 0,77 peritonites/ paciente-ano (NAPRTCS, 2003) e, em 1997, 0,91 peritonites/ paciente-ano (Benfield et al., 1999).

Essas taxas são comparáveis às relatadas pelos centros europeus, mas estão bem acima das menores taxas citadas na literatura, relatadas pelos centros japoneses (Warady et al., 2004).

Segundo o último relato do Registro Pediátrico Japonês, com dados de 22 centros de diálise japoneses, entre os anos de 1999 e 2003, houve 0,17 peritonites/ paciente-ano e 0,29 infecções de óstio / paciente-ano (Hoshii et al., 2006).

Em 2006, foi apresentada em congresso a casuística do centro de diálise peritoneal pediátrico do Hospital Pequeno Príncipe, em Curitiba (PR), entre os anos de 2001 a 2005. Foram avaliados 82 pacientes. Cinqüenta e três pacientes (65\%), apresentaram pelo menos 1 episódio de peritonite, sendo a incidência de peritonites, nessa população, de 1,2 episódios/paciente-ano (Meneses et al., 2006). 
Embora as taxas de peritonite estejam decaindo ao longo dos últimos anos, ainda se observa, em alguns pacientes, peritonites de repetição, sugerindo que os mecanismos de defesa do paciente ainda constituem fator determinante na patogênese dos episódios de infecção relacionados à diálise peritoneal.

\subsubsection{RESPOSTA IMUNOLÓGICA NO PACIENTE PORTADOR DE DRC}

Crianças portadoras de doença renal crônica sabidamente apresentam maior susceptibilidade para o desenvolvimento de infecções. Várias anormalidades do sistema imunológico já foram estudadas nessa população. Os mecanismos envolvidos não são exatamente conhecidos devido à complexidade desse processo multifatorial e à heterogeneidade dos grupos de pacientes estudados. Tanto a uremia quanto o próprio tratamento dialítico estão envolvidos nesse estado de imunodeficiência (Bouts et al., 2004).

Sabe-se que crianças em DP apresentam baixos níveis de IgG sérica e/ou de suas subclasses. Acreditava-se que isso se devia à perda peritoneal de IgG, mas alguns estudos mostram essa deficiência mesmo antes do início da diálise, sugerindo que ela esteja relacionada ao estado urêmico. $\bigcirc$ papel da deficiência de lgG ou de suas subclasses na patogênese da peritonite ainda está sendo estudado. Kuizon et al. (1995) demonstraram relação significativa entre níveis de $\lg G$ e peritonites em crianças em programa de DP. 
Alterações nas respostas mediadas por células $T$ têm sido demonstradas em pacientes com DRC em diálise. Estudos comprovam, em pacientes adultos em diálise, redução no número dos linfócitos T periféricos, havendo redução proporcional de CD4 e CD8. Em crianças, isso não está completamente elucidado. Um único estudo demonstrou redução da resposta proliferativa de linfócitos em crianças com DRC, sendo essa redução mais significativa em crianças submetidas à hemodiálise (Bouts et al., 2004).

Além das alterações imunológicas sistêmicas, a cavidade peritoneal de pacientes em diálise peritoneal crônica é considerada um sítio imunodeficiente em comparação com a cavidade peritoneal de um indivíduo sadio. Os principais fatores responsáveis por isso seriam: deficiência na depuração linfática de microorganismos contaminantes, redução dos níveis de anticorpos, complemento e leucócitos, presença de fatores inibidores de granulócitos e o uso de soluções de diálise não biocompatíveis (Holmes, 2002).

Os macrófagos, que são as células predominantes no efluente peritoneal, constituem a primeira barreira da defesa celular contra a invasão bacteriana. A fagocitose dos microorganismos pelos macrófagos inicia a via clássica de defesa associada à resposta dos leucócitos polimorfonucleares. Acredita-se que as células mesoteliais peritoneais desempenham um papel decisivo nesse processo, através da produção de citocinas e fatores de crescimento, além de expressar várias moléculas de adesão (Holmes, 2002). 
Vários estudos já demonstraram uma relação inversa entre a freqüência de peritonites e a capacidade de opsonização e/ou concentração de IgG no efluente. Alguns estudos têm identificado alterações funcionais em macrófagos de pacientes em diálise peritoneal. Em pacientes que apresentam freqüentes episódios de peritonite, parece haver deficiência na capacidade de lise bacteriana intracelular pelos macrófagos associada à diminuição da produção de interleucina-1 e expressão do receptor Fc (Holmes, 2002).

Além das alterações imunológicas descritas, está bem estabelecido que as soluções de diálise peritoneal utilizadas convencionalmente diminuem, in vitro e em estudos ex vivo, o funcionamento de leucócitos, fibroblastos e células mesoteliais peritoneais. $\mathrm{O} \mathrm{pH}$ ácido e as altas concentrações de lactato inibem a capacidade de fagocitose e o metabolismo oxidativo dos fagócitos peritoneais, além de inibir a capacidade de secreção de citocinas pelas células mesoteliais. A hipertonicidade e as altas concentrações de produtos de degradação da glicose das soluções de diálise também afetam negativamente a função dos fagócitos peritoneais (Holmes, 2002).

\subsection{DIÁLISE NO INSTITUTO DA CRIANCCA E JUSTIFICATIVA DO ESTUDO}

O programa de diálise peritoneal no Instituto da Criança (ICr) do Hospital das Clínicas da Faculdade de Medicina da Universidade de São Paulo (HC FMUSP) teve início no ano de 1994. Inicialmente, os pacientes eram submetidos à realização de diálise peritoneal intermitente (DPI), e, em 
seguida, após treinamento do familiar responsável, realizavam diálise peritoneal ambulatorial contínua (DPAC). Por este método eram realizadas diariamente trocas manuais com bolsas de diálise recebidas no domicílio.

Atualmente, a tendência no serviço é realizar o treinamento das crianças e adolescentes em insuficiência renal pré-dialítica, em regime ambulatorial. Ao final do treinamento, realiza-se internação curta para implante do cateter de Tenckhoff, com alta breve, e início de diálise domiciliar em duas semanas. Reserva-se a diálise peritoneal intermitente (DPI) para pacientes nos quais não houve tempo hábil para colocação ambulatorial do cateter e para aqueles cujas condições sócio-econômicas e habitacionais contra-indiquem a diálise domiciliar. A DPI é realizada em sistema fechado computadorizado, em regime de internação por 24 horas, 2 a 3 vezes por semana, dependendo da função renal residual do paciente. Após o término do procedimento, a criança recebe alta, retornando para a próxima sessão.

Com o advento de máquinas cicladoras, nos últimos anos, as crianças em diálise domiciliar deixaram de realizar troca manual (DPAC) e passaram a realizar diálise peritoneal automatizada (DPA). Nesta modalidade as trocas são feitas pela cicladora, no período noturno, de acordo com programa dialítico pré-estabelecido pela equipe multiprofissional, minimizando o contato manual com as bolsas de diálise. Algumas vezes, no entanto, é necessária a realização de uma troca manual durante o dia, em adição ao regime de diálise noturno, para aumentar a eficiência da diálise. 
Como as peritonites e infecções relacionadas ao cateter de diálise são as complicações mais freqüentes e as principais causas de falência do método, o presente estudo tem por objetivo analisar a ocorrência de tais complicações em nossa população. Estudou-se o período compreendido entre janeiro de 1994, quando foi iniciado o programa de diálise peritoneal crônica nessa unidade, e dezembro de 2005, no intuito de construir uma base histórica de dados que servirá de norte para futuras intervenções nesta área de atuação, visando o aprimoramento do cuidado ao paciente pediátrico em diálise. 
Objetivos 


\section{OBJETIVOS}

\subsection{OBJETIVO GERAL}

Descrever os aspectos demográficos, bacteriológicos e as complicações associadas aos episódios de peritonite e infecções de óstio e túnel de cateter de diálise peritoneal, nos pacientes em programa de diálise peritoneal na Unidade de Nefrologia Pediátrica do Instituto da Criança do HC FMUSP.

\subsection{OBJETIVOS ESPECÍFICOS}

- Analisar os dados demográficos destes pacientes quanto à: idade ao ingresso no programa de diálise, sexo, parâmetros antropométricos, causa primária da doença renal crônica, tempo de permanência no programa de diálise peritoneal, destino dos pacientes após 0 programa de diálise.

- Descrever os aspectos bacteriológicos dos episódios infecciosos diagnosticados, agrupando-os por critério topográfico em: 1) infecções de óstio e túnel; 2) peritonites e 3) peritonites associadas a infecções de óstio e túnel.

- Avaliar a associação entre o agente etiológico e complicações como falha terapêutica, recidiva, colonização do óstio, necessidade de retirada de cateter e perda funcional peritoneal. 
- Descrever e avaliar, nestes pacientes, a freqüência de fatores de risco para peritonite e infecção de óstio e túnel classicamente descritos na literatura pertinente. 
Métodos 


\section{MÉTODOS}

Realizou-se estudo retrospectivo baseado em revisão dos registros de todos os pacientes que estiveram em diálise peritoneal crônica na Unidade de Nefrologia Pediátrica do Instituto da Criança do HC FMUSP, no período compreendido entre janeiro de 1994, quando foi iniciado o programa de diálise peritoneal crônica nessa unidade, e dezembro de 2005.

Foram incluídos todos os pacientes que estiveram em programa de diálise peritoneal crônica no período, cujos prontuários estivessem acessíveis para análise.

Houve 71 pacientes em programa de diálise, dentre os quais 18 não tiveram seus prontuários resgatados. Assim, foram analisados os dados de 53 pacientes.

\subsection{DADOS OBTIDOS DOS PRONTUÁRIOS}

Foram avaliados os seguintes dados demográficos de todos os pacientes:

$>\quad$ Sexo

$>\quad$ Idade ao início do programa de diálise (anos)

$>\quad$ Peso $(\mathrm{kg})$ e estatura $(\mathrm{cm})$ ao início e ao final do programa de diálise

> Causa primária da doença renal crônica

> Tempo de permanência no programa de diálise (meses) e em cada diferente modalidade: 
- DPI (diálise peritoneal intermitente)

- DPA (diálise peritoneal automatizada)

- DPAC (diálise peritoneal ambulatorial contínua)

$>\quad$ Destino dos pacientes após o programa de diálise.

Os seguintes dados de cada episódio infeccioso foram estudados:

$>\quad$ Idade (anos) ao diagnóstico da infecção

$>\quad$ Tipo de aquisição: domiciliar ou hospitalar

$>\quad$ Necessidade de internação para tratamento

$>\quad$ Tempo de internação (dias)

$>\quad$ Modalidade de diálise peritoneal (DPI/DPA/DPAC)

$>$ Agente etiológico isolado na cultura da secreção do óstio e/ou do líquido peritoneal

$>\quad$ Antibioticoterapia utilizada

> Utilização da técnica de selo de antibiótico no cateter (nos casos de peritonite)

Ocorrência de complicações como:

> Nos casos de infecção de óstio e túnel:

- Evolução para peritonite

- Necessidade de retirada do cateter

- Evolução para colonização do óstio.

Nos casos de peritonites:

- Ocorrência de recidiva 
- Necessidade de retirada de cateter

- Evolução para perda funcional peritoneal.

Analisou-se também a presença dos seguintes fatores de risco para peritonite e infecção de óstio classicamente descritos na literatura pertinente: idade, história de cirurgia abdominal prévia à entrada no programa de diálise crônica, presença de derivações abdominais (gastrostomia, ureterostomia e vesicostomia) durante a realização da diálise, uso de antibiótico profilático para passagem do cateter de diálise peritoneal, modalidade de diálise (DPI/DPA/DPAC), intervalo de tempo (dias) entre a implantação do cateter e início da diálise, hipoalbuminemia, presença de vazamentos pelo óstio do cateter após sua utilização e realização de diálise peritoneal prévia.

\subsection{ANÁLISE ESTATÍSTICA}

Realizou-se análise descritiva dos dados demográficos dos pacientes e dos episódios infecciosos.

As infecções foram analisadas em três grupos divididos segundo critério topográfico:

$>$ Infecções de óstio e túnel

$>$ Peritonites

> Peritonites associadas a infecções de óstio e túnel 
As infecções de óstio e túnel foram agrupadas na mesma categoria para efeito de análise. Calculou-se a densidade de incidência de infecções em cada grupo.

A análise dos dados de peso e estatura dos pacientes foi realizada pelo cálculo do escore Z de estatura/idade, peso/idade e índice de massa corpórea (IMC)/idade e pela correlação peso/idade e estatura/idade, segundo as curvas NCHS / CDC (NCHS, 2000). Utilizou-se o software GraphPad, Prism 4 para a análise estatística desses dados.

Avaliou-se a freqüência de possíveis fatores de risco para infecção em todos os pacientes e em dois grupos: pacientes com e sem infecção. Foi aplicado teste exato de Fisher para verificar a associação entre as variáveis estudadas e infecção. A comparação das medianas foi realizada pelo teste de Mann-Whitney.

As densidades de incidência de infecção nas diferentes modalidades de diálise (DPA/DPAC/DPI) foram calculadas e comparadas entre si pelo cálculo do escore Z (Horan 1993).

Para a análise das complicações (colonização do óstio, retirada do cateter e perda funcional peritoneal) foram criados gráficos dos riscos de cada complicação por agente etiológico, com os intervalos de confiança de 95\%. Posteriormente, agrupou-se os agentes bacterianos em gram-positivos e gram-negativos, e comparou-se a associação destes grupos com as complicações infecciosas pelo teste do qui-quadrado.

Adotou-se nível de significância estatística de 5\%. 


\subsection{DEFINICÕES}

Considerou-se como infecção hospitalar ao episódio infeccioso instalado após pelo menos 48 horas de internação ou quando o paciente estivesse em esquema de diálise peritoneal intermitente na Unidade de Diálise Peritoneal.

Peritonite foi definida como presença de líquido peritoneal turvo, acompanhado de dor abdominal e/ou febre, associado ao achado de mais de 100 leucócitos $/ \mathrm{mm}^{3}$ no exame citológico do líquido peritoneal, sendo pelo menos $50 \%$ polimorfonucleares (Warady et al., 2000).

Classificou-se como recidiva de peritonite à recorrência de peritonite com o mesmo agente dentro de 4 semanas após término do tratamento (Warady et al., 2000).

Considerou-se infecção de óstio do cateter à presença de eritema e secreção purulenta no óstio, com ou sem cultura positiva. Infecção de túnel foi caracterizada como dor, edema e eritema do trajeto subcutâneo do túnel do cateter de diálise (Warady et al., 2000).

Definiu-se falha terapêutica quando não houve melhora dos sintomas após 72 horas de antibioticoterapia.

Definiu-se hipoalbuminemia como albumina sérica inferior a 3,5 g/dL.

As modalidades de diálise peritoneal realizadas no período estudado obedecem ao seguinte padrão descritivo:

- Diálise peritoneal ambulatorial contínua (DPAC): regime de DP manual, com realização de 4 a 5 trocas diárias, de modo que haja solução de diálise na cavidade peritoneal continuamente. 
- Diálise peritoneal automatizada (DPA): realização de DP por meio de máquina cicladora, consistindo de várias trocas noturnas de curta duração. Dependendo da função renal residual do paciente, após término da diálise, a cavidade peritoneal pode ser totalmente esvaziada ou uma pequena quantidade de líquido pode ser deixada. Algumas vezes associa-se uma troca manual diurna para incrementar a eficiência da diálise.

- Diálise peritoneal intermitente (DPI): realização de DP em regime de internação na Unidade de Diálise por 24 horas, 2 a 3 vezes por semana, dependendo da função renal residual.

\subsection{PROTOCOLO DE TRATAMENTO}

No período estudado, utilizou-se cefalexina oral associada ao uso tópico de mupirocina para tratamento de primoinfecções de óstio de aquisição domiciliar. Para o tratamento de peritonites, utilizaram-se, nos casos de aquisição domiciliar, cefalosporina de primeira geração ou terceira geração e, nos de aquisição hospitalar, vancomicina associada à cefalosporina de terceira ou quarta geração Nos casos de infecções de óstio e peritonites recorrentes, outros antibióticos eram utilizados, individualizando a escolha conforme cada caso.

A técnica de selo de antibiótico no cateter de diálise foi utilizada como adjuvante à antibioticoterapia parenteral nos casos de peritonite, na tentativa de evitar retirada do cateter, quando o paciente apresentava bom estado 
geral, melhora dos sintomas clínicos e da celularidade do líquido peritoneal, com manutenção de cultura positiva no líquido peritoneal. 
Resultados 


\section{RESULTADOS}

Os dados demográficos dos 53 pacientes estudados estão descritos na tabela 1.

Tabela 3- Dados demográficos dos pacientes relativos a sexo, idade cronológica, em anos, ao início da diálise (mediana, valor máximo e valor mínimo), etiologia da doença renal crônica, destino dos pacientes após diálise peritoneal, seqüência de modalidade de diálise, tempo em diálise, em meses (mediana, valor máximo e valor mínimo)

\begin{tabular}{|c|c|}
\hline & $\begin{array}{l}\text { № pacientes (\%) } \\
(n=53)\end{array}$ \\
\hline $\begin{array}{l}\text { Sexo } \\
\\
\text { Masculino } \\
\text { Feminino }\end{array}$ & $\begin{array}{l}32(60,4 \%) \\
21(39,6 \%)\end{array}$ \\
\hline $\begin{array}{l}\text { Etiologia da DRC } \\
\text { Má-formação urológica } \\
\text { Glomerulopatias } \\
\text { Tubulopatias } \\
\text { Outras causas* }\end{array}$ & $\begin{array}{c}32(60,4 \%) \\
15(28,3 \%) \\
4(7,5 \%) \\
2(3,8 \%)\end{array}$ \\
\hline $\begin{array}{l}\text { Destino dos pacientes após diálise } \\
\text { Transplante renal } \\
\text { Em diálise peritoneal ao final do estudo } \\
\text { Hemodiálise } \\
\text { Transferência para diálise de adultos } \\
\text { Óbito** }\end{array}$ & $\begin{aligned} 26 & (49 \%) \\
15 & (28,3 \%) \\
10 & (18,9 \%) \\
1 & (1,9 \%) \\
1 & (1,9 \%)\end{aligned}$ \\
\hline $\begin{array}{l}\text { Seqüência de modalidade de diálise } \\
\text { DPI } \rightarrow \text { DPA } \\
\text { Somente DPA } \\
\text { DPAC } \rightarrow \text { DPA } \\
\text { DPI } \rightarrow \text { DPAC } \\
\text { DPI } \rightarrow \text { DPAC } \rightarrow \text { DPA } \\
\text { Somente DPAC } \\
\text { Somente DPI }\end{array}$ & $\begin{array}{l}21(39,6 \%) \\
12(22,6 \%) \\
7(13,2 \%) \\
4(7,5 \%) \\
4(7,5 \%) \\
3(5,7 \%) \\
2(3,8 \%)\end{array}$ \\
\hline $\begin{array}{l}\text { Mediana da idade (anos) ao início da diálise (min- } \\
\text { max) }\end{array}$ & $9,5(0,3$ a 18,2$)$ \\
\hline $\begin{array}{l}\text { Mediana do tempo (meses) em diálise (min-max) } \\
\text { Total } \\
\text { DPI } \\
\text { DPAC } \\
\text { DPA }\end{array}$ & $\begin{array}{c}20,5(3,9 \text { a } 87,1) \\
2,4(0,1 \text { a } 15,3) \\
11,6(2,4 \text { a } 25,8) \\
16,5(3,3 \text { a } 65,9)\end{array}$ \\
\hline
\end{tabular}

\subsection{ANÁLISE DE PESO E ESTATURA DOS PACIENTES}

O gráfico 1 descreve a análise do escore $Z$ de peso/idade, estatura/idade e índice de massa corpórea (IMC)/idade dos pacientes, ao início do programa de diálise. Os gráficos $2, \quad 3$ e 4 descrevem, 
respectivamente, a comparação do escore $Z$ de estatura/idade, peso/idade e IMC/idade ao início e ao final do programa de diálise, ou ao final do período de seguimento.

Gráfico 2 - Cálculo do escore $Z$ de estatura/idade (Est/ld $z$ ), peso/idade (Peso/ld z), e IMC/idade (IMC/ld z) dos pacientes ao início do programa de diálise peritoneal

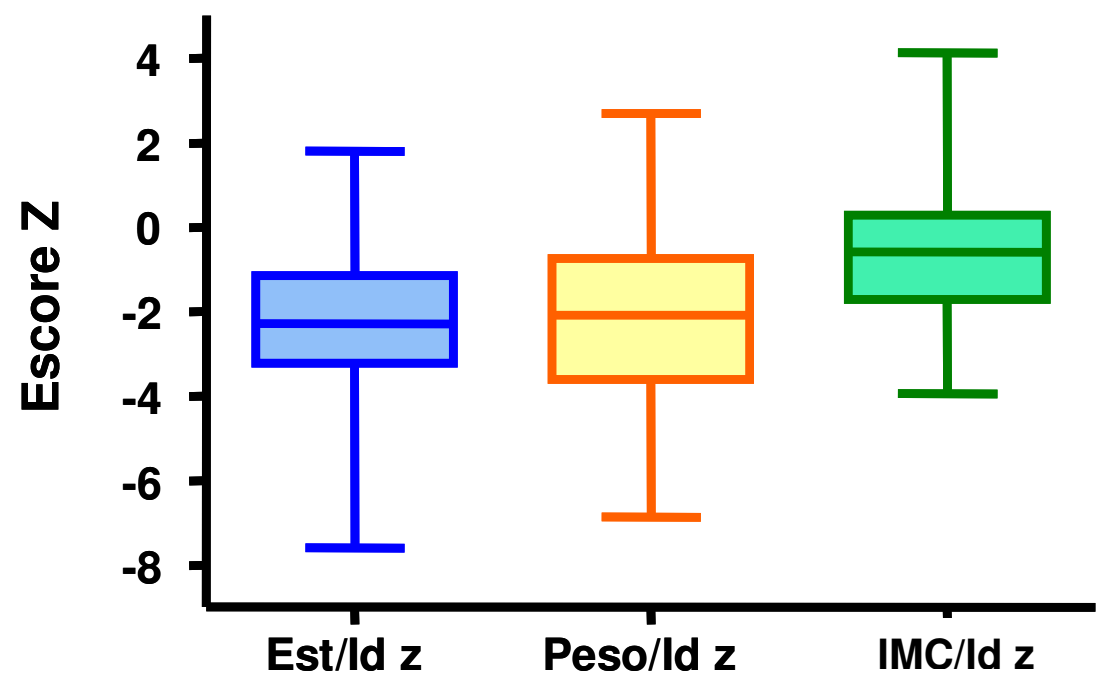

Gráfico 2 - Comparação do escore $Z$ de estatura/idade (Z E/I) dos pacientes ao início (i) e ao final (f) do programa de diálise peritoneal

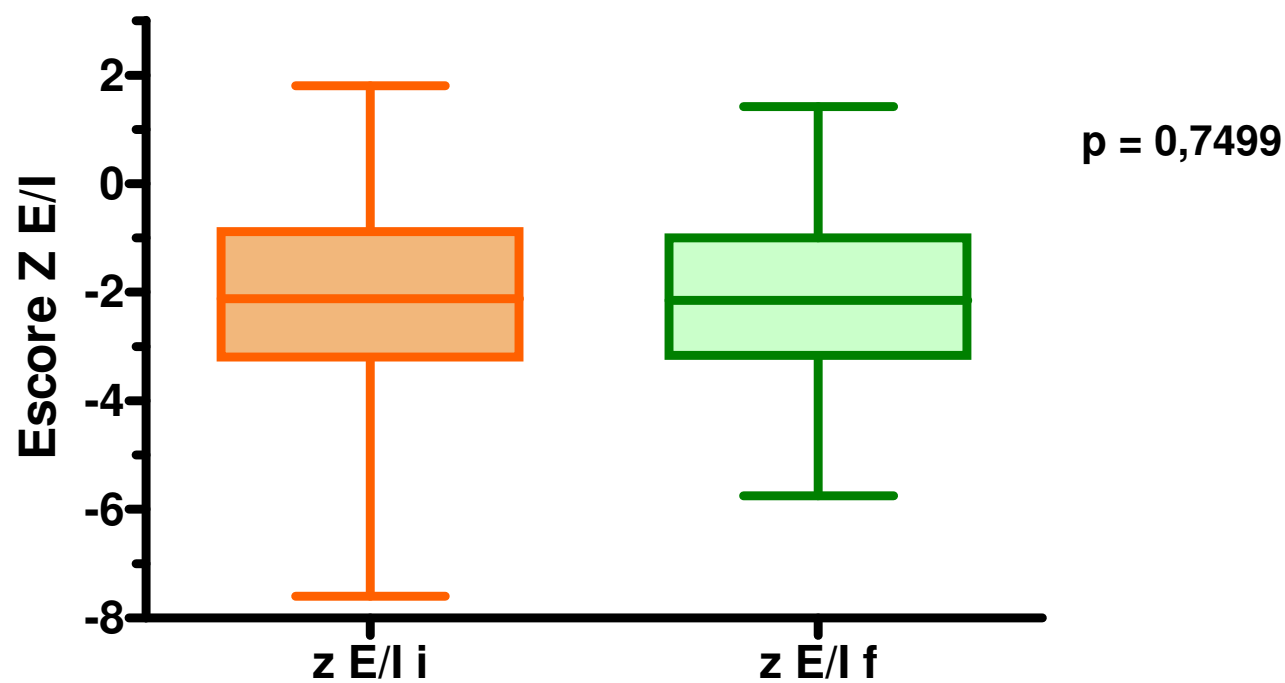


Gráfico 3 - Comparação do escore $Z$ de peso/idade (Z P/I) dos pacientes ao início (i) e ao final (f) do programa de diálise peritoneal

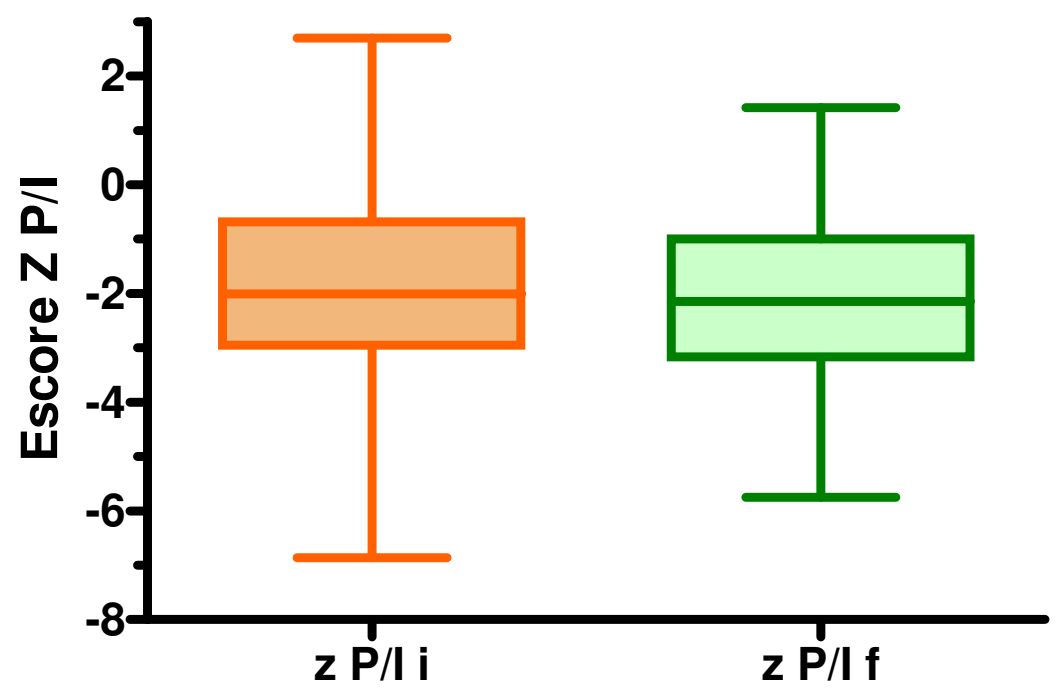

Gráfico 4 - Comparação do escore Z de IMC/idade (Z IMC/id) dos pacientes ao início (i) e ao final (f) do programa de diálise peritoneal

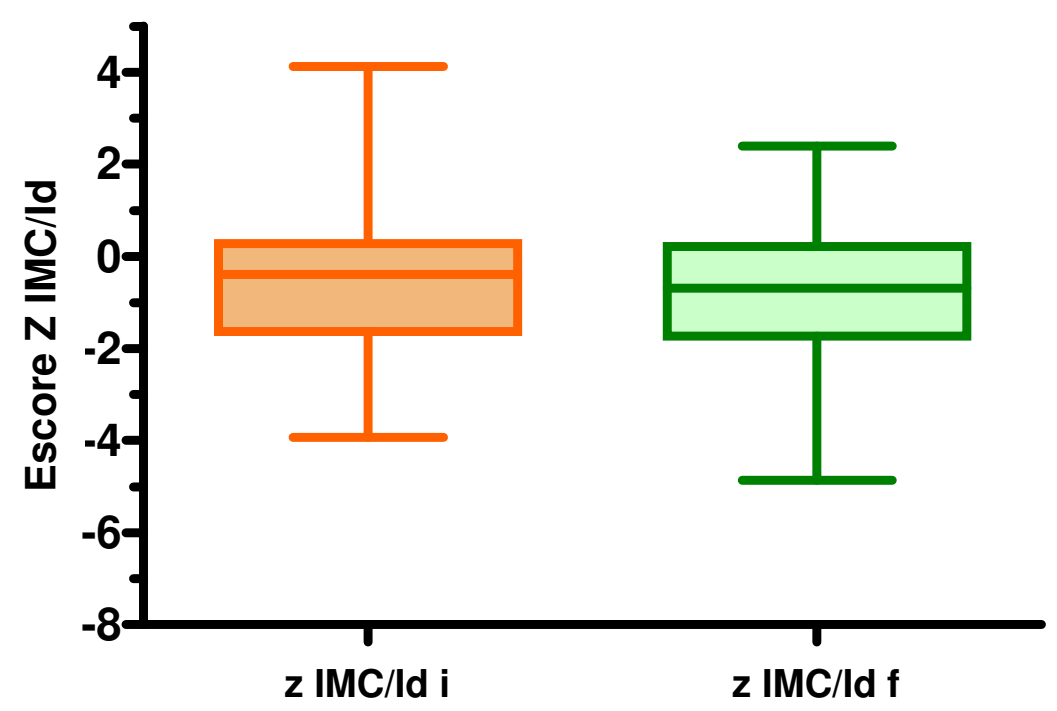

$p=0,2568$ 


\subsection{ANÁLISE DOS EPISÓDIOS INFECCIOSOS}

Houve 132 episódios infecciosos no período observado, em 42 (79\%) pacientes, sendo 65 peritonites, 51 infecções de óstio, 3 infecções de óstio e túnel, 12 infecções de óstio associadas a peritonite e 1 infecção de óstio e túnel associada a peritonite. As infecções de óstio e túnel foram agrupadas na mesma categoria para efeito de análise.

Tabela 4 - Análise dos episódios infecciosos segundo densidade de incidência de infecção, em episódios/paciente-ano, tipo de aquisição, necessidade de internação, tempo de internação (mediana, intervalo interquartil $25 \%-75 \%$ ou IQ25-75), em dias, idade ao diagnóstico (mediana, IQ25-75), em meses, e modalidade de diálise ao diagnóstico

\begin{tabular}{|l|c|c|c|}
\hline & $\begin{array}{c}\text { Óstio } \\
(\mathbf{n = 5 4 )}\end{array}$ & $\begin{array}{c}\text { Peritonite } \\
(\mathbf{n = 6 5 )}\end{array}$ & $\begin{array}{c}\text { Óstio + Peritonite } \\
(\mathbf{n}=13)\end{array}$ \\
\hline $\begin{array}{l}\text { Densidade de incidência } \\
\text { de infecção } \\
\text { (episódios/paciente-ano) }\end{array}$ & 0,49 & 0,59 & 0,12 \\
\hline
\end{tabular}

\begin{tabular}{|c|c|c|c|}
\hline $\begin{array}{l}\text { Aquisição } \\
\text { Domiciliar } \\
\text { Hospitalar }\end{array}$ & $\begin{array}{l}43(79,6 \%) \\
11(20,4 \%)\end{array}$ & $\begin{array}{l}53(81,5 \%) \\
12(18,5 \%)\end{array}$ & $\begin{array}{c}13(100 \%) \\
0\end{array}$ \\
\hline $\begin{array}{l}\text { Necessidade de } \\
\text { internação }\end{array}$ & $10(18,5 \%)$ & 58 (89\%) & $12(92 \%)$ \\
\hline $\begin{array}{l}\text { Mediana do tempo (dias) } \\
\text { de internação (IQ25-75)* }\end{array}$ & 18 (9 a 25,5) & 11 (5 a 22) & $10,5(7,3$ a 14,8$)$ \\
\hline $\begin{array}{l}\text { Mediana da idade (anos) } \\
\text { ao diagnóstico (IQ25-75) }\end{array}$ & $7,7(5,0$ a 13,1$)$ & $11,3(7,5$ a 14,3$)$ & $8,6(7,6$ a 9,9$)$ \\
\hline $\begin{array}{l}\text { Modalidade de diálise ao } \\
\text { diagnóstico } \\
\text { DPA } \\
\text { DPAC } \\
\text { DPI } \\
\text { Antes da diálise }\end{array}$ & $\begin{array}{c}32(59,3 \%) \\
12(22,2 \%) \\
9(16,7 \%) \\
1(1,9 \%)\end{array}$ & $\begin{array}{c}41(63 \%) \\
16(24,6 \%) \\
8(12,3 \%) \\
0\end{array}$ & $\begin{array}{c}8(62 \%) \\
5(38 \%) \\
0 \\
0\end{array}$ \\
\hline
\end{tabular}

*IQ25-75: intervalo interquartil 25\%-75\%

\subsection{INFECCÕES DE ÓSTIO ASSOCIADAS OU NÃO A INFECCÃO DO}

\section{TÚNEL DO CATETER DE DIÁLISE (ÓSTIO/TÚNEL)}

Houve 54 episódios de infecção de óstio/túnel, 11 delas de aquisição hospitalar, em 27 (51\%) pacientes, sendo 51 episódios de infecção de óstio 
e 3 episódios de infecção de óstio associada a túnel, em 110,8 pacientesano. Assim sendo, houve 0,49 episódios/ paciente-ano.

\subsubsection{AGENTES ETIOLÓGICOS NAS INFECCÕ̃ES DE ÓSTIO/TÚNEL DO}

\section{CATETER DE DIÁLISE}

A tabela 3 descreve o número de agentes isolados nas culturas de secreção de óstio nos 54 episódios de infecção de óstio/túnel do cateter de diálise. Observamos que a cultura da secreção de óstio foi negativa em 7 (13\%) episódios. Em 43 (79\%) episódios, apenas um agente foi isolado na cultura de secreção de óstio e em 4 (8\%) episódios, mais de um agente foi isolado.

A tabela 4 descreve os agentes encontrados nos episódios de infecção de óstio/túnel em que a cultura da secreção de óstio foi positiva, seja em cultura isolada ou em cultura mista.

A tabela 5 descreve os agentes envolvidos nos casos de infecções hospitalares.

Tabela 3 - Número (№) de agentes isolados nas culturas de secreção de óstio nos 54 episódios de infecção de óstio/túnel do cateter de diálise № de agentes isolados № episódios (\%) $(n=54)$

\begin{tabular}{|c|c|}
\hline 1 & $43(79 \%)$ \\
\hline 2 & $2(4 \%)$ \\
\hline 3 & $2(4 \%)$ \\
\hline CULTURA NEGATIVA & $7(13 \%)$ \\
\hline
\end{tabular}


Tabela 4 - Agentes etiológicos isolados nas culturas positivas de secreção de óstio nos episódios de infecção de óstio/túnel do cateter de diálise Agente etiológico $\%$ isolamento de cada agente $(n=53)$

Staphylococcus aureus

Staphylococcus coagulase negativo

Pseudomonas aeruginosa

Corynebacterium

Acinetobacter baumanii

Streptococcus $\beta$-hemolítico do grupo $F$

Streptococcus grupo viridans

Proteus mirabilis

Serratia marcescens

Escherichia coli

Klebsiella pneumoniae

Enterobacter aerogenes

Moraxella catarralis
$23(43,4 \%)$

$7(13,2 \%)$

$7(13,2 \%)$

$6(11,3 \%)$

$2(3,7 \%)$

$1(1,9 \%)$

$1(1,9 \%)$

$1(1,9 \%)$

$1(1,9 \%)$

$1(1,9 \%)$

$1(1,9 \%)$

$1(1,9 \%)$

$1(1,9 \%)$

Tabela 5 - Agentes etiológicos isolados nas culturas de secreção de óstio nos 11 episódios de infecções de óstio/túnel do cateter de diálise de aquisição hospitalar

Agente etiológico

№ episódios (\%)

$(n=11)$

Staphylococcus aureus

$4(36 \%)$

Acinetobacter baumanii

CULTURA NEGATIVA

$2(18 \%)$

$2(18,5 \%)$

Klebsiella pneumoniae

S. aureus + Klebsiella pneumoniae

$1(9 \%)$

$1(9 \%)$

Corynebacterium

$1(9 \%)$ 


\subsubsection{TRATAMENTO DAS INFECÇÕES DE ÓSTIO/TÚNEL DO CATETER}

\section{DE DIÁLISE}

A maioria dos casos foi tratada inicialmente com cefalexina ou ciprofloxacina por via oral, empiricamente, até resultado de culturas, em associação ao uso tópico de mupirocina. Outros antibióticos utilizados estão descritos na tabela 6 .

Tabela 6 - Antibioticoterapia inicial empírica nos 54 episódios de infecção de óstio/túnel do cateter de diálise

\begin{tabular}{|l|c|}
\hline Antibiótico & $\begin{array}{c}\text { № episódios (\%) } \\
(\mathbf{n = 5 4 )}\end{array}$ \\
\hline Cefalexina & $20(37 \%)$ \\
\hline Ciprofloxacina & $13(24 \%)$ \\
\hline Ceftriaxone & $3(6 \%)$ \\
\hline Vancomicina & $3(6 \%)$ \\
\hline Amoxacilina & $2(4 \%)$ \\
\hline Teicoplamina & $2(4 \%)$ \\
\hline Ceftazidima & $2(4 \%)$ \\
\hline Cefalotina & $1(2 \%)$ \\
\hline Rifampicina & $1(2 \%)$ \\
\hline Cotrimoxazol & $1(2 \%)$ \\
\hline Cefoxitina & $1(2 \%)$ \\
\hline Vancomicina + ceftriaxone & $1(2 \%)$ \\
\hline Vancomicina + cefepime & $1(2 \%)$ \\
\hline Apenas mupirocina tópica* & $1(2 \%)$ \\
\hline Limpeza tópica do óstio com água oxigenada* & $2(4 \%)$ \\
\hline * nos casos de cultura da secreção do óstio positiva para Corynebacterium
\end{tabular}

Em 48 (89\%) episódios, foi mantido o antibiótico inicial até o final do tratamento, o qual foi realizado, em média, por 14,5 dias (5 a 25 dias).

Em 6 (11\%) episódios, houve necessidade de troca do antibiótico utilizado inicialmente. Em 4 casos, por falha terapêutica inicial; em 1 caso, a troca foi realizada para adequação de antibioticoterapia após resultado de 
antibiograma (descalonamento) e, em 1 caso, por reação adversa medicamentosa.

Dentre os 20 pacientes que receberam inicialmente cefalexina, apenas em $2(10 \%)$ casos houve necessidade de troca de antibiótico, em um dos casos por reação adversa medicamentosa e no outro por falha terapêutica. Neste caso o agente isolado na cultura da secreção do óstio era S. aureus sensível a cefalotina.

Quanto aos 13 pacientes que receberam inicialmente ciprofloxacina, houve necessidade de troca de antibiótico em 2 (15\%) casos, por falha terapêutica. Nos dois casos isolaram-se Pseudomonas aeruginosa multissensível e houve necessidade de retirada do cateter. A escolha da ciprofloxacina como antibiótico inicial empírico foi guiada por culturas anteriores. A maioria destes pacientes apresentava infecções de repetição e/ou eram colonizados por Pseudomonas aeruginosa; um destes pacientes era colonizado por Enterobacter aerogenes e outro por S. aureus.

\subsubsection{COMPLICAC̣̃̃ES NAS INFECCÕ̃ES DE ÓSTIO/TÚNEL DO}

\section{CATETER DE DIÁLISE}

Houve necessidade de retirada do cateter em 5 casos $(9 \%)$ de infecção de óstio/túnel, como mostra a tabela 7.

Tabela 7 - Agentes etiológicos isolados nas culturas de secreção de óstio nos 5 episódios de infecções de óstio/túnel em que foi necessária a retirada do cateter Agente etiológico № episódios (\%) $(n=5)$ 
Houve evolução para peritonite em 2 (4\%) episódios, ambos na mesma paciente, a qual apresentou múltiplos episódios de infecção de óstio e colonização por $S$. aureus.

Em 14 (26\%) episódios, houve evolução para colonização do óstio do cateter, como mostra a tabela 8. Dois destes pacientes, com história de colonização por Pseudomonas aeruginosa, apresentavam extrusão do "cuff" e dois pacientes, colonizados por $S$. aureus, apresentavam granuloma de "cuff".

Tabela 8 - Agentes etiológicos isolados nas culturas de secreção de óstio nos 14 episódios de infecções de óstio/túnel que evoluíram com colonização do óstio

Agente etiológico

№ episódios(\%) $(n=14)$

Staphylococcus aureus

$7(50 \%)$

Pseudomonas aeruginosa $3(21 \%)$

Corynebacterium $2(14 \%)$

Enterobacter aerogenes $1(7 \%)$

Proteus mirabilis + Corynebacterium + $1(7 \%)$

Staphylococcus coagulase negativo

As tabelas 9 a 12 demonstram a porcentagem de complicações nas infecções de óstio/túnel de acordo com os principais agentes etiológicos.

Tabela 9 - Complicações nos 23 episódios de infecção de óstio/túnel causados por S. aureus

\section{Complicação}

Colonização do óstio

Retirada do cateter

Evolução para peritonite
№ episódios (\%)

$(n=23)$

$7(30 \%)$

0

$2(9 \%)$ 
Tabela 10 - Complicações nos 7 episódios de infecção de óstio/túnel causados por Pseudomonas aeruginosa

\begin{tabular}{|l|c|}
\hline Complicação & $\begin{array}{c}\text { № episódios (\%) } \\
(\mathbf{n = 7 )}\end{array}$ \\
\hline Colonização do óstio & $3(43 \%)$ \\
\hline Retirada do cateter & $3(43 \%)$ \\
\hline Evolução para peritonite & 0 \\
\hline
\end{tabular}

Tabela 11 - Complicações nos 7 episódios de infecção de óstio/túnel causados por Staphylococcus coagulase negativo

\begin{tabular}{|l|c|}
\hline $\begin{array}{l}\text { Complicação } \\
\text { Colonização do óstio }\end{array}$ & $\begin{array}{c}\text { No episódios (\%) } \\
(\mathbf{n = 7 )}\end{array}$ \\
\hline Retirada do cateter & 0 \\
\hline Evolução para peritonite & $1(14 \%)$ \\
\hline
\end{tabular}

Tabela 12 - Complicações nos 4 episódios de infecção de óstio/túnel causados por Corynebacterium

\begin{tabular}{|l|c|}
\hline Complicação & $\begin{array}{c}\text { №. episódios (\%) } \\
(\mathbf{n = 4 )}\end{array}$ \\
\hline Colonização do óstio & $2(50 \%)$ \\
\hline Retirada do cateter & 0 \\
\hline Evolução para peritonite & 0 \\
\hline
\end{tabular}

\subsubsection{ANÁLISE ISOLADA DAS INFECCÕES DE TÚNEL DO CATETER}

Houve 3 episódios de infecção de óstio e túnel do cateter. Os agentes isolados foram S. aureus em 2 casos e Proteus mirabilis, Staphylococcus. coagulase negativo e Corynebacterium no outro caso. Em 2 casos houve evolução para colonização do óstio, em um caso por $S$. aureus e em outro por Proteus mirabilis e Corynebacterium. Não houve evolução para peritonite nem necessidade de retirada do cateter em nenhum caso. 


\subsection{PERITONITES}

Foram observados 65 episódios de peritonite não associados a infecção de óstio, 12 deles de aquisição hospitalar, em 32 (60\%) pacientes, em 110,8 pacientes-ano. Assim sendo, houve 0,59 episódios /paciente-ano.

\subsubsection{AGENTES ETIOLÓGICOS NAS PERITONITES}

A tabela 13 descreve o número de agentes isolados nas culturas de líquido peritoneal nos 65 episódios de peritonite. Observamos que a cultura do líquido peritoneal foi negativa em 16 (25\%) peritonites. Em 43 (66\%) peritonites, apenas um agente foi isolado na cultura de secreção de óstio e em $6(9 \%)$ peritonites, mais de um agente foi isolado.

A tabela 14 descreve os agentes encontrados nas peritonites em que a cultura do líquido peritoneal foi positiva.

A tabela 15 descreve os agentes envolvidos nas 12 peritonites de aquisição hospitalar.

Tabela 13 - Número (№.) de agentes isolados nas culturas de líquido peritoneal nos 65 episódios de peritonite № de agentes isolados № episódios (\%)

$(n=65)$

1 $43(66 \%)$ 2 


\begin{tabular}{|l|c|}
$\begin{array}{l}\text { Tabela } 14 \text { - Agentes etiológicos isolados nas culturas positivas de líquido peritoneal } \\
\text { nos episódios de peritonite }\end{array}$ & $\begin{array}{c}\text { \% isolamento de cada } \\
\text { agente } \\
\text { (n=55) }\end{array}$ \\
\hline Agente etiológico & $15(27 \%)$ \\
\hline Staphylococcus aureus & $13(24 \%)$ \\
\hline Staphylococcus coagulase negativo & $4(7 \%)$ \\
\hline Acinetobacter baumanii & $3(5 \%)$ \\
\hline Streptococcus grupo viridans & $3(5 \%)$ \\
\hline Haemophilus influenzae & $2(4 \%)$ \\
\hline Proteus mirabilis & $2(4 \%)$ \\
\hline Serratia marcescens & $2(4 \%)$ \\
\hline Klebsiella pneumoniae & $1(1,8 \%)$ \\
\hline Pseudomonas aeruginosa & $1(1,8 \%)$ \\
\hline Enterobacter cloacae & $1(1,8 \%)$ \\
\hline Acinetobacter wolffi & $1(1,8 \%)$ \\
\hline Neisseria subflava & $1(1,8 \%)$ \\
\hline Enterocbacter gergovia & $1(1,8 \%)$ \\
\hline Streptococcus grupo D & $1(1,8 \%)$ \\
\hline Streptococcus mitis & $1(1,8 \%)$ \\
\hline Streptococcus sanguis & $1(1,8 \%)$ \\
\hline Candida parapsilosis & $1(1,8 \%)$ \\
\hline Candida guilhermondi & $1(1,8 \%)$ \\
\hline Candida albicans & \begin{tabular}{c}
$15 \%)$ \\
\hline
\end{tabular} \\
\hline
\end{tabular}

\begin{tabular}{|l|c|}
$\begin{array}{l}\text { Tabela } \mathbf{1 5} \text { - Agentes etiológicos isolados nas culturas de líquido peritoneal nos } \mathbf{1 2} \\
\text { episódios de peritonite de aquisição hospitalar }\end{array}$ \\
\begin{tabular}{|l|c|}
\hline Agente etiológico & № episódios (\%) \\
& $(\mathbf{n = 1 2 )}$
\end{tabular} \\
\hline Staphylococcus aureus & $4(33,3 \%)$ \\
\hline Cultura negativa & $4(33,3 \%)$ \\
\hline Staphylococcus coagulase negativo & $1(8,3 \%)$ \\
\hline Serratia marcescens & $1(8,3 \%)$ \\
\hline Klebsiella pneumoniae & $1(8,3 \%)$ \\
\hline Candida parapsilosis & $1(8,3 \%)$ \\
\hline
\end{tabular}




\subsubsection{TRATAMENTO DAS PERITONITES}

A maioria dos pacientes foi tratada inicialmente com ceftriaxone. A tabela 16 detalha os antibióticos utilizados para terapia inicial empírica, até resultado de culturas.

\begin{tabular}{|l|c|}
\hline $\begin{array}{l}\text { Tabela } 16 \text { - Antibioticoterapia inicial empírica nos } 65 \text { casos de peritonite } \\
\text { Antibiótico }\end{array}$ & $\begin{array}{c}\text { episódios (\%) } \\
(\mathbf{n}=65)\end{array}$ \\
\hline Ceftriaxone & $28(43 \%)$ \\
\hline Vancomicina & $12(18,5 \%)$ \\
\hline Cefepima & $6(9,2 \%)$ \\
\hline Vancomicina+cefepima & $5(7,7 \%)$ \\
\hline Vancomicina+ceftriaxone & $3(4,6 \%)$ \\
\hline Cefotaxima & $3(4,6 \%)$ \\
\hline Cefalotina & $2(3 \%)$ \\
\hline Ciprofloxacina & $1(1,5 \%)$ \\
\hline Imipenem & $1(1,5 \%)$ \\
\hline Teicoplamina & $1(1,5 \%)$ \\
\hline Teicoplamina+ceftazidima & $1(1,5 \%)$ \\
\hline Oxacilina + cefotaxima & $1(1,5 \%)$ \\
\hline Vancomicina+cefotaxima & $1(1,5 \%)$ \\
\hline
\end{tabular}

Em 30 (46\%) episódios, foi mantido o antibiótico utilizado inicialmente até o final do tratamento, sendo a média de tratamento de 13,7 (6 a 21) dias.

Em 35 (54\%) episódios, houve troca do antibiótico inicial. Em 5 (14\%) casos, por falha terapêutica inicial, e em 1 (3\%) caso por reação adversa medicamentosa. Em 15 (43\%) casos realizou-se a troca para terminar antibioticoterapia por via oral; em $14(40 \%)$ casos, a troca foi realizada após resultado de antibiograma (descalonamento). 
Dentre os 28 pacientes que receberam inicialmente ceftriaxone, houve troca em $16(57 \%)$ casos. Em 7 (25\%) casos a troca foi realizada para adequação do tratamento após resultado de antibiograma (descalonamento). Em $6(21 \%)$ casos foi realizada troca para terminar antibioticoterapia por via oral. Apenas em 3 (11\%) casos a troca foi motivada por falha terapêutica. Em um desses 3 casos, o agente era Staphylococcus aureus resistente a oxacilina e, em outro, Staphylococcus coagulase negativo também resistente a oxacilina, sendo trocado ceftriaxone por vancomicina, com boa resposta. No outro caso, o agente era Serratia marcescens, sendo trocado ceftriaxone para ciprofloxacina, com base em antibiograma, e depois para cefepime, com associação de selo de amicacina no cateter. Não houve boa resposta, apesar de o antibiograma evidenciar sensibilidade a todos esses antibióticos, e houve evolução para perda funcional peritoneal, sendo necessária a retirada do cateter e transferência do paciente para hemodiálise.

\subsubsection{UTILIZAÇÃO DA TÉCNICA DE SELO DE ANTIBIÓTICO NO} CATETER DE DIÁLISE

O uso coadjuvante da técnica de selo de antibiótico no cateter de diálise peritoneal foi realizado em 15 episódios de peritonite (em 12 pacientes) e em um episódio de peritonite associada à infecção de óstio, sendo realizada, portanto, em 16 casos. Esta técnica preveniu a retirada do cateter em 10 (67\%) episódios de peritonite nas quais foi utilizada.

A sua utilização nos 15 episódios de peritonite está descrita na tabela 17. 
Tabela 17 - Agentes etiológicos envolvidos, antibióticos, doses, tempo de uso e eficácia nos 15 casos de peritonite em que foi utilizado selo de antibiótico no cateter de diálise

\begin{tabular}{|c|c|c|c|c|c|}
\hline & Agente etiológico & Antibiótico & $\begin{array}{c}\text { Dose } \\
\text { ( } \mathrm{mg} / \mathrm{mL})\end{array}$ & $\begin{array}{c}\text { Tempo } \\
\text { (dias) }\end{array}$ & Eficácia \\
\hline $1^{*}$ & S.aureus (oxaS) ${ }^{\star \star *}$ & Cefalotina & 5 & 7 & Sim \\
\hline $2^{*}$ & S.aureus (oxaS) & Vancomicina & 1 & 17 & Não \\
\hline 3 & Candida guilhermondi & Anfotericina B & 0,1 & 20 & Não \\
\hline 4 & Candida albicans & Anfotericina B & 0,1 & 12 & Não \\
\hline 5 & Serratia marcescens & Gentamicina & 5 & 16 & Sim \\
\hline 6 & Acinetobacter baumanii & Amicacina & 5 & 10 & Sim \\
\hline 7 & S.aureus (oxaS) & Vancomicina & 10 & 21 & Não \\
\hline 8 & Serratia marcescens & Gentamicina & 5 & 4 & Não \\
\hline 9 & S.aureus (oxaS) & Cotrimoxazol & 5 ( sulfa) & 20 & Sim \\
\hline 10 & $\begin{array}{l}\text { Staphylococcus coagulase } \\
\text { negativo (oxaS) }\end{array}$ & Cefalotina & 5 & 14 & Sim \\
\hline 11 & $\begin{array}{l}\text { Staphylococcus coagulase } \\
\text { negativo (oxaS) }\end{array}$ & Cefalotina & 5 & 14 & Sim \\
\hline 12 & $\begin{array}{l}\text { Staphylococcus coagulase } \\
\text { negativo (oxaR) }{ }^{\star \star \star *}\end{array}$ & Vancomicina & 4 & 21 & Sim \\
\hline $13^{* *}$ & S.aureus (oxaS) & Cefazolina & 5 & 14 & Sim \\
\hline $14^{* *}$ & S.aureus (oxaS) & Cefazolina & 5 & 14 & Sim \\
\hline $15^{\star \star}$ & S.aureus (oxaS) & Cefazolina & 5 & 14 & Sim \\
\hline
\end{tabular}

* Estes dois episódios ocorreram na mesma paciente, a qual evoluiu com perda funcional peritoneal sendo transferida para hemodiálise.

** Estes 3 episódios de peritonite por $S$. aureus ocorreram no mesmo paciente, sendo utilizado selo de cefazolina com sucesso, mas o paciente mantinha recidiva de peritonites a cada mês até a data final do período de observação

${ }^{* * *}$ oxaS: oxacilina-sensível

${ }^{* * *}$ oxaR:oxacilina-resistente 


\subsubsection{COMPLICACÕES RELACIONADAS AOS EPISÓDIOS DE}

\section{PERITONITE}

Houve necessidade de retirada do cateter em 14 casos (22\%) e evolução para perda funcional peritoneal em 7 casos (11\%). As tabelas $18 \mathrm{e}$ 19 descrevem os agentes envolvidos.

Tabela 18 - Agentes etiológicos nos 14 episódios de peritonite em que foi necessária a retirada do cateter de diálise

\begin{tabular}{|l|c|}
\hline Agente etiológico & $\begin{array}{c}\text { No episódios (\%) } \\
(\mathbf{n = 1 4 )}\end{array}$ \\
\hline Staphylococcus aureus & $3(21 \%)$ \\
\hline Staphylococcus coagulase negativo & $2(14 \%)$ \\
\hline Candida guilhermondi & $1(7 \%)$ \\
\hline Candida albicans & $1(7 \%)$ \\
\hline Candida parapsilosis & $1(7 \%)$ \\
\hline Serratia marcescers & $1(7 \%)$ \\
\hline Acinetobacter baumanii & $1(7 \%)$ \\
\hline Pseudomonas aeruginosa + & $1(7 \%)$ \\
\hline Proteus mirabilis & $1(7 \%)$ \\
\hline Staphylococcus coagulase negativo + Acinetobacter wolffii & $1(7 \%)$ \\
\hline Klebsiella pneumoniae + Acinetobacter baumanii & $1(7 \%)$ \\
\hline Cultura negativa & \\
\hline
\end{tabular}

Tabela 19 - Agentes etiológicos nos 7 episódios de peritonite em que houve evolução para perda funcional peritoneal

\begin{tabular}{|l|c|}
\hline $\begin{array}{l}\text { para perda funcional peritoneal } \\
\text { Agente etiológico }\end{array}$ & $\begin{array}{c}\text { No episódios (\%) } \\
(\mathbf{n}=7)\end{array}$ \\
\hline S. aureus & $1(14,3 \%)$ \\
\hline Proteus mirabilis & $1(14,3 \%)$ \\
\hline Serratia marcescers & $1(14,3 \%)$ \\
\hline Klebsiella pneumoniae & $1(14,3 \%)$ \\
\hline Candida albicans & $1(14,3 \%)$ \\
\hline Candida parapsilosis & $1(14,3 \%)$ \\
\hline Cultura negativa & $1(14,3 \%)$ \\
\hline
\end{tabular}


Recidiva da peritonite ocorreu apenas em um episódio, após dois dias da alta hospitalar. Os agentes etiológicos envolvidos foram Klebisiella pneumoniae e Enterobacter cloacae isolados no líquido peritoneal no primeiro episódio e Klebisiella pneumoniae e Acinetobacter baumanii no segundo episódio. Nesse caso houve necessidade de retirada do cateter, com evolução para perda funcional peritoneal, sendo a paciente transferida para hemodiálise.

As tabelas 20 a 23 demonstram a porcentagem de complicações de acordo com os principais agentes nas peritonites.

Tabela 20 - Complicações nos 15 episódios de peritonite causados por S. aureus Complicação № episódios (\%)

\begin{tabular}{|l|c|}
\hline Retirada do cateter & $(\mathbf{n = 1 5 )}$ \\
\hline Perda funcional peritoneal & $3(20 \%)$ \\
\hline
\end{tabular}

Tabela 21 - Complicações nos 13 episódios de peritonite causados por Staphylococcus coagulase negativo

\begin{tabular}{l|c|}
\hline Complicação & $\begin{array}{c}\text { No episódios (\%) } \\
(\mathbf{n = 1 3 )}\end{array}$ \\
\hline Retirada do cateter & $3(23 \%)^{*}$ \\
\hline Perda funcional peritoneal & 0 \\
\hline * em um desses casos, havia associação com Acinetobacter wolffi
\end{tabular}


Tabela 22 - Complicações nos 4 episódios de peritonite causados por Acinetobacter baumanii

\begin{tabular}{|l|c|}
\hline Complicação & $\begin{array}{c}\text { № episódios (\%) } \\
(\mathbf{n = 4})\end{array}$ \\
\hline Retirada do cateter & $2(50 \%)^{*}$ \\
\hline Perda funcional peritoneal & $1(25 \%)^{*}$ \\
\hline
\end{tabular}

* mesmo episódio, no qual também foi isolada Klebsiella pneumoniae

Tabela 23 - Complicações nos 3 episódios de peritonite causados por Candida sp Complicação № episódios (\%) $(n=3)$

Retirada do cateter $3(100 \%)$

Perda funcional peritoneal $2(67 \%)$

No único episódio de peritonite em que foi isolada Pseudomonas aeruginosa, houve necessidade de retirada do cateter e evolução para perda funcional peritoneal.

\subsection{PERITONITES ASSOCIADAS A INFECCÕES DE ÓSTIO/TÚNEL DO}

\section{CATETER}

Houve 13 episódios de peritonite associada à infecção de óstio, em 8 (15\%) pacientes, sendo 12 infecções de óstio associadas a peritonite e 1 infecção de óstio e túnel associada a peritonite, em 110,8 paciente-ano. Assim sendo, houve 0,12 episódios/paciente-ano. 


\subsubsection{AGENTES ETIOLÓGICOS NAS PERITONITES ASSOCIADAS A} INFECCÕES DE ÓSTIO/TÚNEL DO CATETER

A positividade da cultura e os agentes encontrados nas culturas de secreção de óstio e do líquido peritoneal estão descritas nas tabelas 24 e 25. A tabela 26 descreve os agentes encontrados em cada episódio.

Tabela 24 - Número (№) de agentes isolados nas culturas dos 13 episódios de peritonites associadas a infecções de óstio/túnel

№ de agentes isolados $\quad$ № culturas (\%)

\section{Cultura da secreção de óstio}

1

$9(69 \%)$

Cultura negativa

$4(31 \%)$

Cultura do líquido peritoneal

1

Cultura negativa

Tabela 25 - Agentes etiológicos isolados nas culturas dos 13 episódios de peritonites associadas a infecções de óstio/túnel

Agente etiológico

№ culturas (\%)

\section{Cultura de secreção de óstio}

Staphylococcus aureus

$6(67 \%)$

Staphylococcus coagulase negativo

$2(22 \%)$

Corynebacterium

$1(11 \%)$

Cultura de líquido peritoneal

Staphylococcus aureus

$1(20 \%)$

Staphylococcus coagulase negativo

$1(20 \%)$

Pseudomonas aeruginosa

$1(20 \%)$

Enterobacter cloacae

$1(20 \%)$

Stenotrophomonas matophilia

$1(20 \%)$ 
Tabela 26 - Agentes etiológicos isolados em cada episódio de peritonite associada a infecção de óstio/túnel

\begin{tabular}{|c|l|l|}
\hline Episódios & Cultura de óstio & Cultura de líquido peritoneal \\
\hline $\mathbf{1}$ & Cultura negativa & Cultura negativa \\
\hline $\mathbf{2}$ & Cultura negativa & Cultura negativa \\
\hline $\mathbf{3}$ & S. aureus & S. aureus \\
\hline $\mathbf{4}$ & S. aureus & Cultura negativa \\
\hline $\mathbf{5}$ & S. aureus & Staphylococcus coagulase negativo \\
\hline $\mathbf{6}$ & Staphylococcus coagulase negativo & Cultura negativa \\
\hline $\mathbf{7}$ & Cultura negativa & Cultura negativa \\
\hline $\mathbf{8}$ & Staphylococcus coagulase negativo & Cultura negativa \\
\hline $\mathbf{9}$ & S. aureus & Cultura negativa \\
\hline $\mathbf{1 0}$ & S. aureus & Cultura negativa \\
\hline $\mathbf{1 1}$ & S. aureus & Enterobacter cloacae \\
\hline $\mathbf{1 2}$ & Cultura negativa & Pseudomonas aeruginosa \\
\hline $\mathbf{1 3}$ & Corynebacterium & Stenotrophomonas maltophilia \\
\hline
\end{tabular}

\subsubsection{TRATAMENTO DAS PERITONITES ASSOCIADAS A INFECCÕES DE}

\section{ÓSTIO/TÚNEL DO CATETER}

A maioria dos pacientes foi tratada inicialmente com ceftriaxone. A tabela 27 detalha os antibióticos utilizados inicialmente nos demais casos.

Tabela 27 - Antibioticoterapia inicial empírica nos 13 casos de peritonite associada a infecção de óstio/túnel do cateter

\begin{tabular}{|l|c|}
\hline Antibiótico & $\begin{array}{c}\text { No episódios (\%) } \\
(\mathbf{n = 1 3 )}\end{array}$ \\
\hline Ceftriaxone & $4(31 \%)$ \\
\hline Teicoplamina & $2(15 \%)$ \\
\hline Ceftazidima & $1(7,7 \%)$ \\
\hline Cefalotina & $1(7,7 \%)$ \\
\hline Ciprofloxacina & $1(7,7 \%)$ \\
\hline Vancomicina+ceftriaxone & $1(7,7 \%)$ \\
\hline Teicoplamina+ceftriaxone & $1(7,7 \%)$ \\
\hline Vancomicina+cefepima & $1(7,7 \%)$ \\
\hline Vancomicina+cefotaxima & $1(7,7 \%)$ \\
\hline
\end{tabular}


Em 6 (46\%) episódios, foi mantido o antibiótico inicial até o final do tratamento. Em 5 (38\%) episódios ele foi trocado, em 1 caso por falha terapêutica, em 2 casos devido a adequação pelo antibiograma (descalonamento) e, em 2 casos, para completar o tratamento por via oral. Em 2 (15\%) episódios houve necessidade de associação de outros antibióticos, em um deles por falha terapêutica inicial e no outro por infecção por outro agente durante o tratamento. Assim sendo, houve falha terapêutica do antibiótico empírico inicial apenas em 2 (15\%) casos.

Dentre os 4 pacientes que receberam inicialmente ceftriaxone, apenas em 1 caso foi realizada troca para cefalotina, após resultado de antibiograma.

A técnica adjuvante de selo de antibiótico foi utilizada em 1 caso, em que o agente isolado foi Stenotrophomonas maltophilia no líquido peritoneal, sendo utilizado selo de cotrimoxazol $(10 \mathrm{mcg} / \mathrm{mL})$, por 38 dias, com boa resposta.

\subsubsection{COMPLICAÇÕES NAS PERITONITES ASSOCIADAS A INFECCOÕES DE ÓSTIO/TÚNEL DO CATETER}

Houve necessidade de troca do cateter em 3 (23\%) casos e evolução para perda funcional peritoneal em 2 (15\%) casos, nos mesmos pacientes, em que os agentes envolvidos foram $S$. aureus e Pseudomonas aeruginosa. Não houve evolução para colonização do óstio em nenhum episódio.

As tabelas 28 e 29 descrevem os agentes encontrados nas peritonites associadas a infecções de óstio/túnel em que houve necessidade de retirada 
do cateter e perda funcional peritoneal. A tabela 30 descreve a porcentagem de complicações nos casos de peritonite associada a infecção de óstio/túnel nos quais foram isolados $S$. aureus.

Tabela 28 - Agentes etiológicos nos 3 episódios de peritonites associadas a infecções de óstio/túnel em que foi necessária a retirada do cateter

\begin{tabular}{c|l|l|} 
Episódios & Cultura de óstio & Cultura de líquido peritoneal \\
\hline $\mathbf{1}$ & S. aureus & S. aureus \\
$\mathbf{2}$ & Negativa & P. aeruginosa \\
$\mathbf{3}$ & Negativa & Negativa \\
\hline
\end{tabular}

Tabela 29 - Agentes etiológicos nos 2 episódios de peritonites associadas a infecções de óstio/túnel em que houve evolução para perda funcional peritoneal

\begin{tabular}{|c|l|l|}
\hline Episódios & Cultura de óstio & Cultura de líquido peritoneal \\
\hline $\mathbf{1}$ & S. aureus & S. aureus \\
\hline $\mathbf{2}$ & Negativa & P. aeruginosa \\
\hline
\end{tabular}

Tabela 30 - Complicações nos 6 episódios de peritonite associada a infecção de óstio/túnel causados por Staphylococcus aureus

Tipo de Complicação

\begin{tabular}{|l|c|}
\hline Tipo de Complicação & $\begin{array}{c}\text { № episódios (\%) } \\
(\mathbf{n}=6)\end{array}$ \\
\hline Retirada do cateter & $1(17 \%)$ \\
\hline Perda funcional peritoneal & $1(17 \%)$ \\
\hline
\end{tabular}

No único episódio em que foi isolada Pseudomonas aeruginosa, houve necessidade de retirada do cateter e evolução para perda funcional peritoneal. Não houve complicações em nenhum dos 3 episódios em que foi isolado Staphylococcus coagulase negativo. 
4.5.4 ANÁLISE DO EPISÓDIO ISOLADO DE INFECC̣ÃO DE TÚNEL DO CATETER ASSOCIADA A PERITONITE

Houve um único episódio de infecção de túnel associada a peritonite, no qual a cultura de secreção do óstio foi positiva para $S$. aureus e a cultura de líquido peritoneal foi positiva para Staphylococcus coagulase negativo. $\mathrm{O}$ paciente foi tratado inicialmente com ceftriaxone, sendo trocado para cefalotina após antibiograma, com boa evolução.

\subsection{ANÁLISE DAS COMPLICACÕ̃ES NOS 3 GRUPOS DE INFECCCÃO}

Os gráficos 5 a 10 descrevem a análise de perda funcional peritoneal, evolução para colonização do óstio e necessidade de retirada de cateter de acordo com o agente etiológico. O gráfico 11 analisa a necessidade de retirada de cateter de acordo com o grupo de infecção. 
Gráfico 5 - Análise dos episódios em que houve perda funcional peritoneal de acordo com os agentes etiológicos, nos casos de peritonite e peritonite associada a infecção de óstio/túnel. Risco de perda funcional peritoneal com intervalo de confiança de $95 \%$

Associação entre perda funcional peritoneal e agente etiológico

(peritonite e óstio+peritonite)

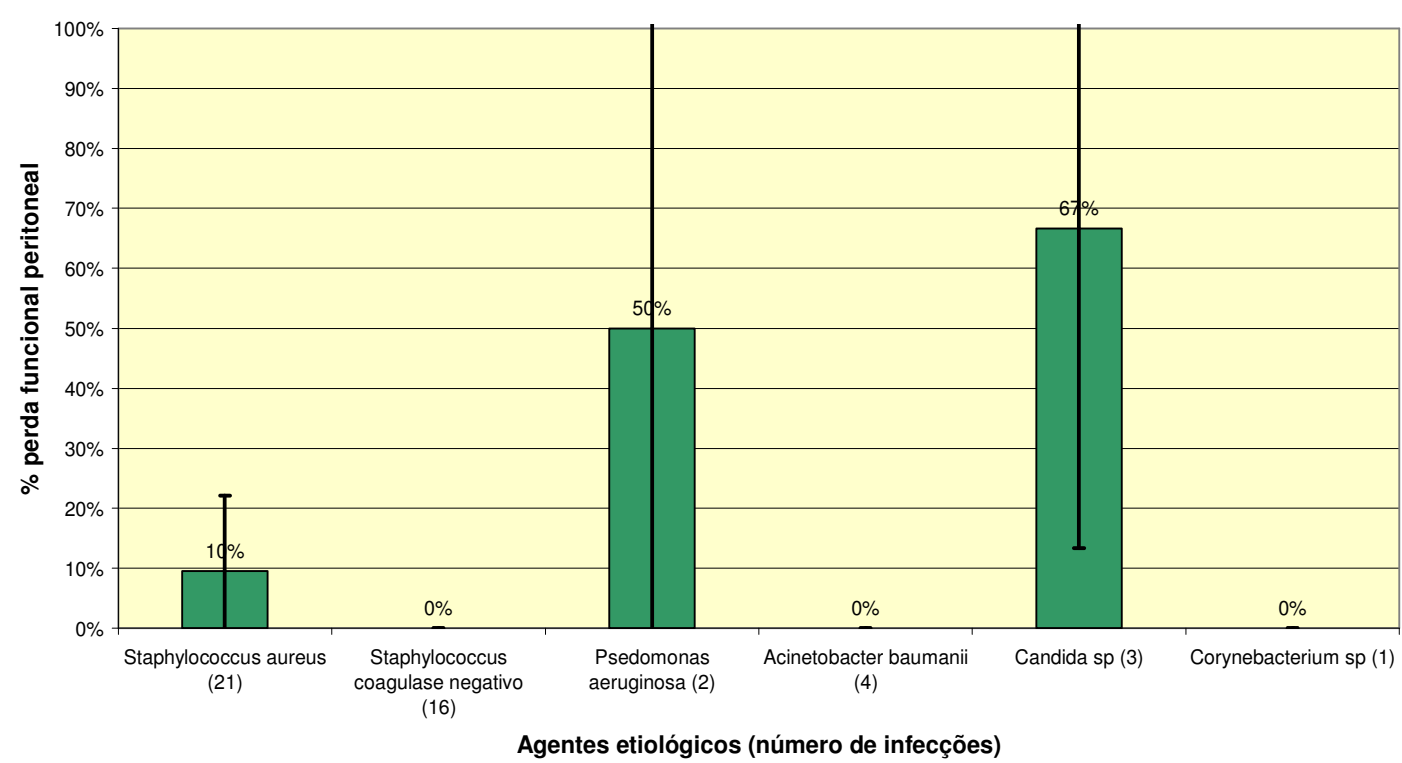

Gráfico 6 - Análise dos episódios em que houve perda funcional peritoneal de acordo com o tipo de agente bacteriano: gram-positivos (gram+) e gramnegativos (gram-). Risco de perda funcional peritoneal com intervalo de confiança de $95 \%$

Associação entre perda funcional peritoneal e tipo de agente etiológico $(p=0,064)$

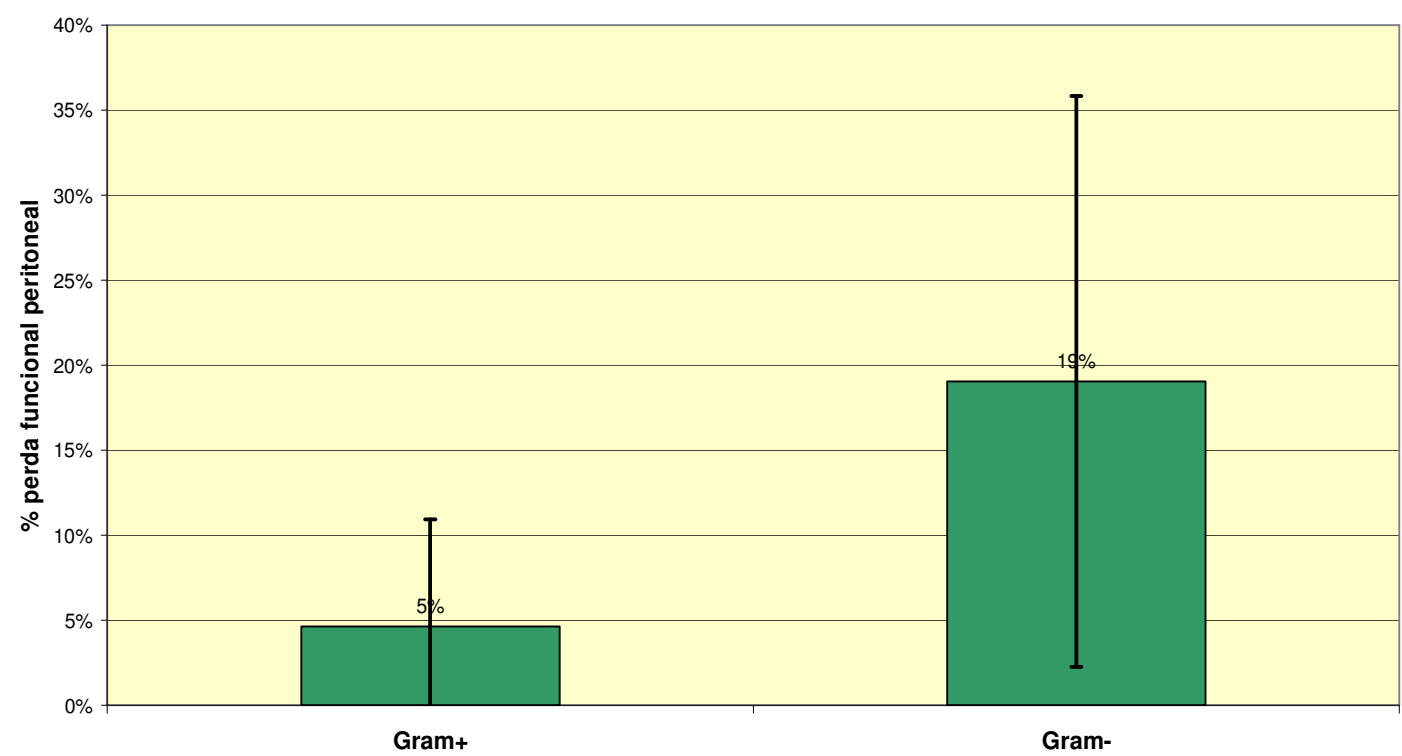


Gráfico 7 - Análise dos episódios em que houve evolução para colonização do óstio de acordo com os agentes etiológicos, nos casos de infecções de óstio e peritonites associadas a infecção de óstio. Risco de colonização com intervalo de confiança de $95 \%$

Associação entre colonização do óstio e agente etiológico

(óstio e óstio+peritonite)

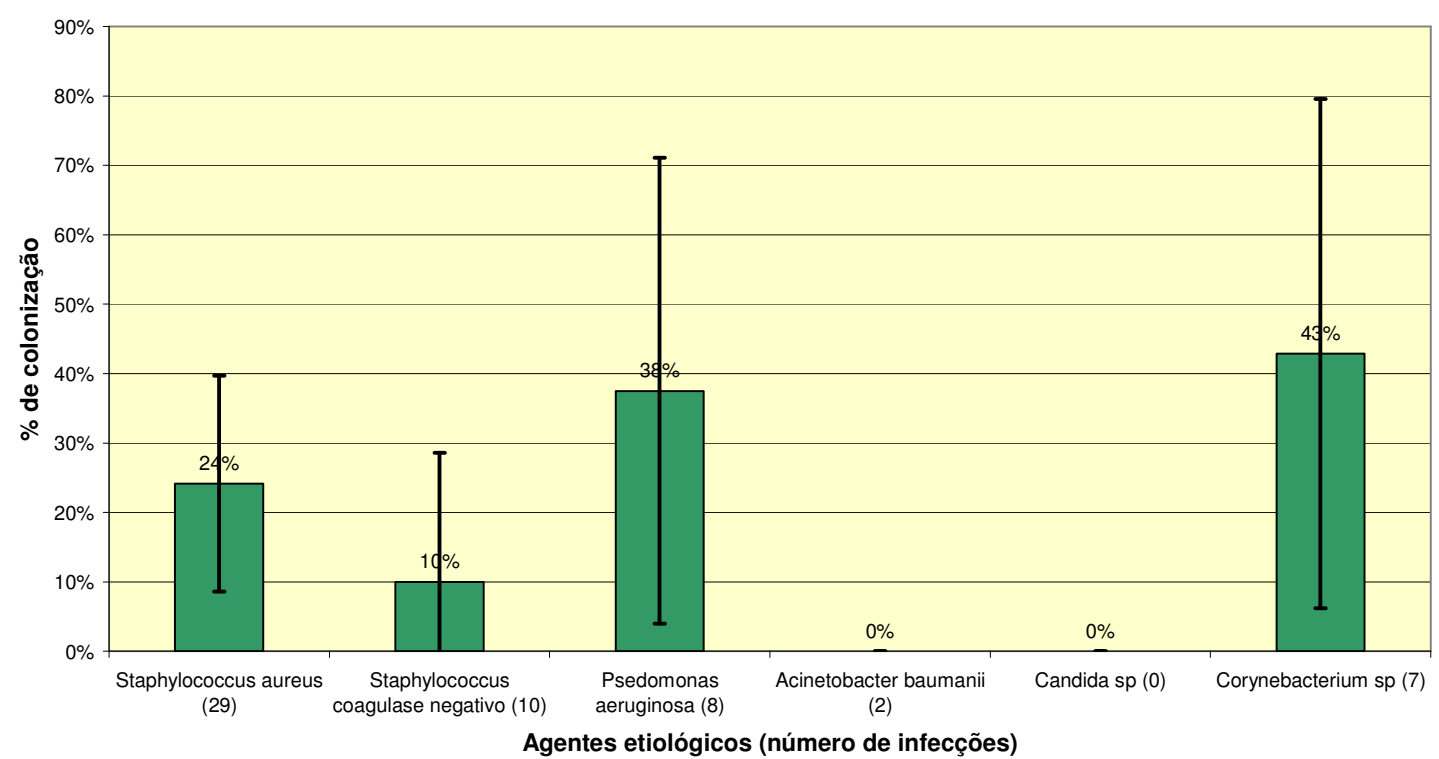

Gráfico 8 - Análise dos episódios em que houve evolução para colonização do óstio de acordo com o tipo de agente bacteriano: gram-positivos (gram+) e gram-negativos (gram-). Risco de colonização com intervalo de confiança de $95 \%$

Associação entre colonização do cateter e tipo de agente etiológico $(p=0,714)$

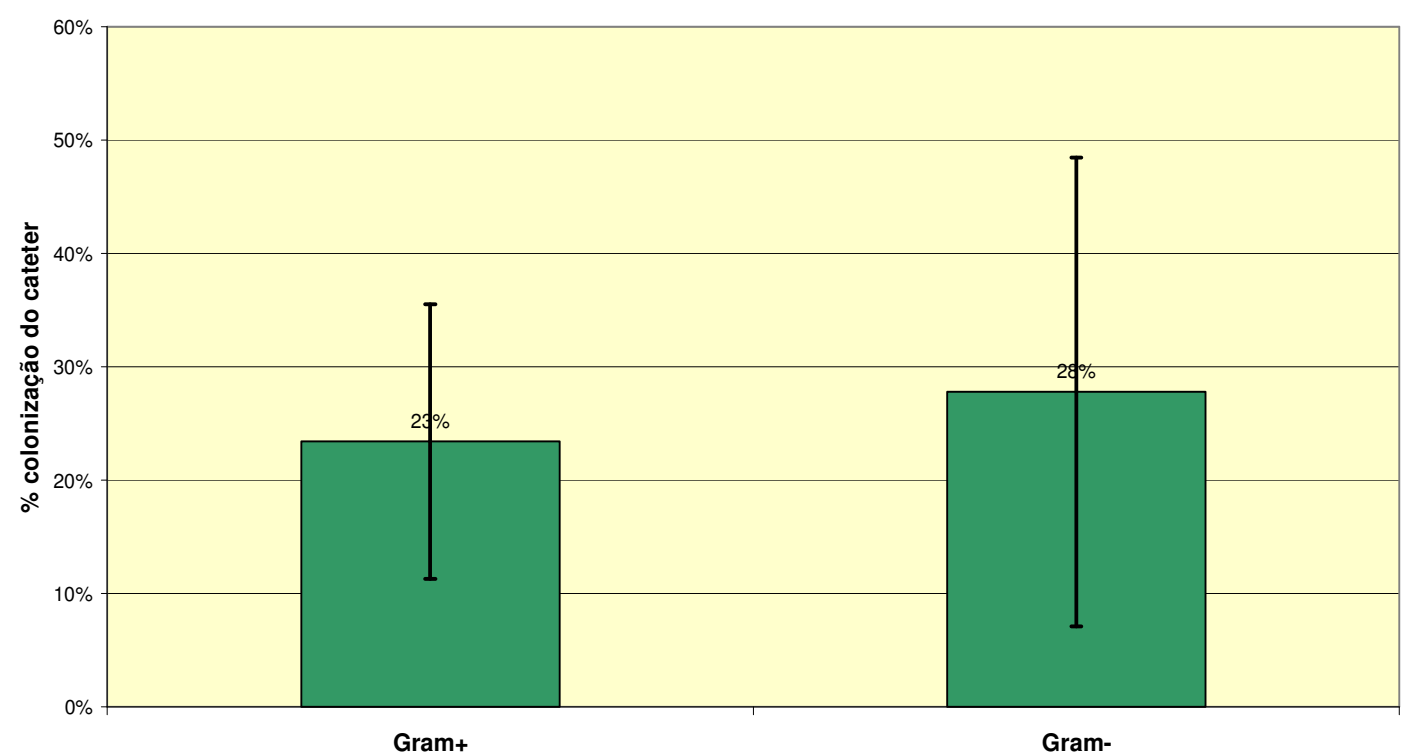


Gráfico 9 - Análise dos casos em que houve necessidade de retirada do cateter de acordo com os agentes etiológicos, nos três grupos de infecção. Risco de retirada com intervalo de confiança de $95 \%$

Associação entre retirada de cateter e agente etiológico

(óstio, peritonite e óstio+peritonite)

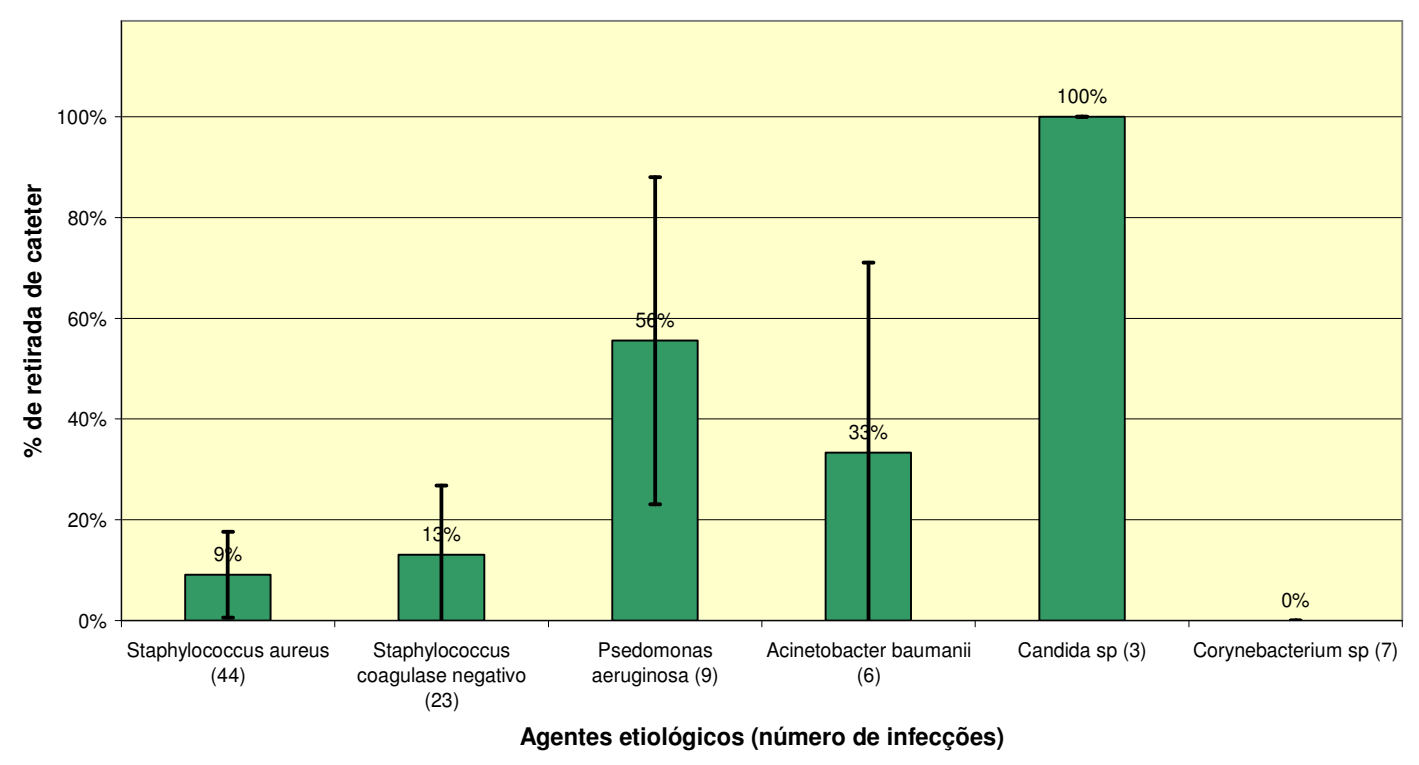

Gráfico 10 - Análise dos casos em que houve necessidade de retirada do cateter de acordo com o tipo de agente bacteriano: gram-positivos (gram+) e gram-negativos (gram-). Risco de retirada com intervalo de confiança de $95 \%$

Associação entre retirada de catéter e tipo do agente etiológico $(p=0,013)$

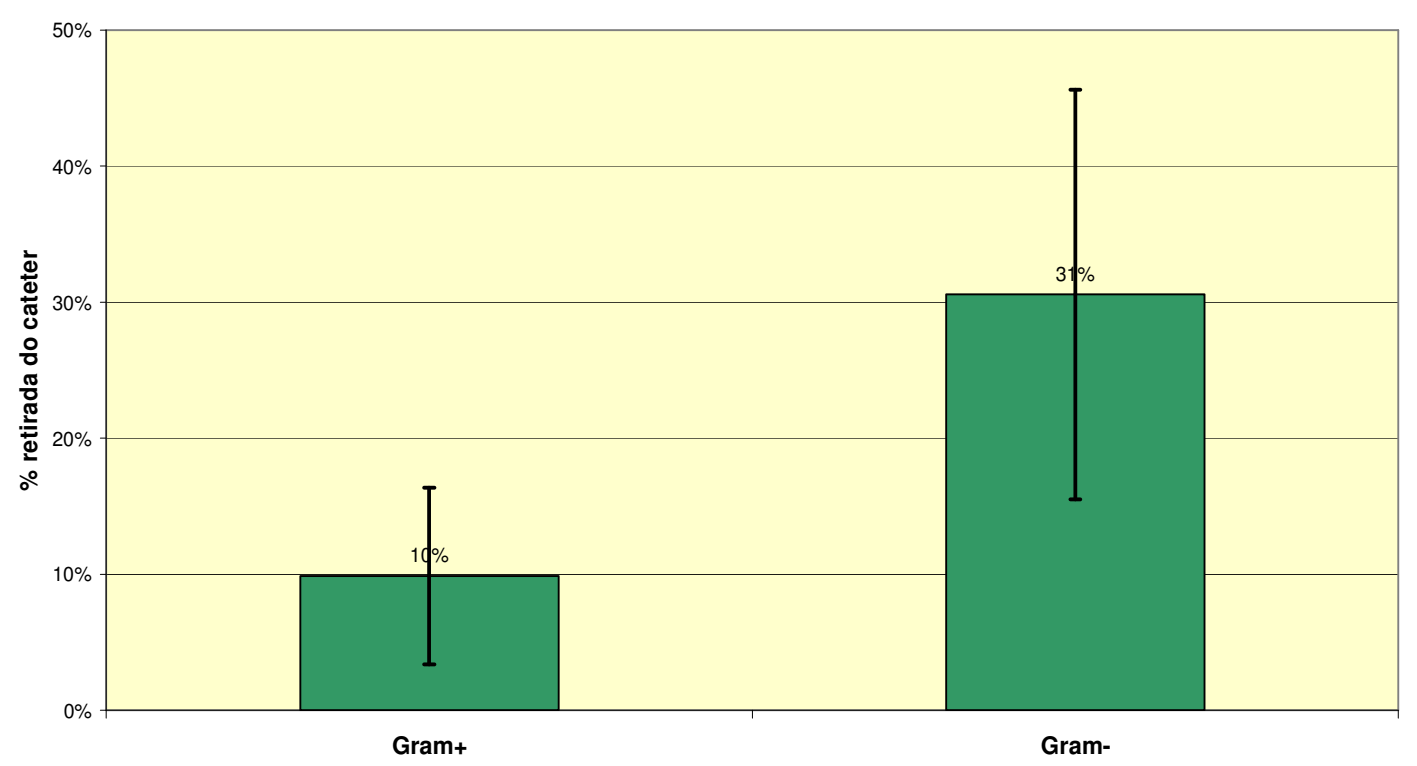


Gráfico 11 - Análise dos episódios em que houve necessidade de retirada do cateter de acordo com o grupo de infecção. Risco de retirada com intervalo de confiança de $95 \%$

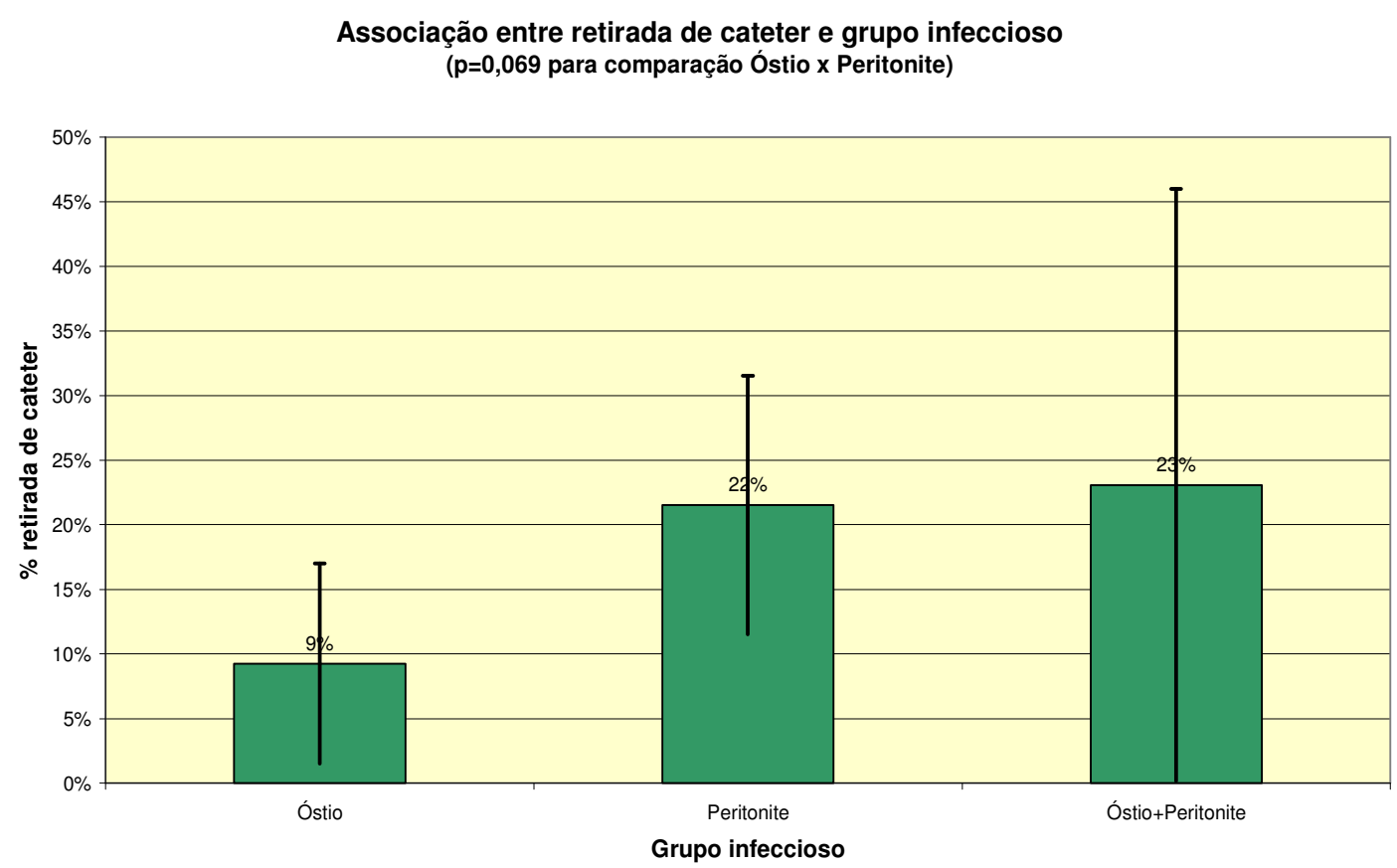

\subsection{ANÁLISE DOS POSSÍVEIS FATORES DE RISCO PARA INFECCÃO}

A tabela 31 descreve a freqüência dos fatores de risco classicamente relacionados, na literatura pertinente, a infecções relacionadas ao cateter de diálise e peritonites. A análise destes dados pelo teste exato de Fisher ou pelo teste de Mann-Whitney não permitiu estabelecer correlação estatisticamente significante entre os fatores estudados e infecção.

Calculamos as densidades de incidência de infecção nas diferentes modalidades de diálise nas três categorias de infecções estudadas (infecções de óstio/túnel, peritonites e peritonites associadas a infecções de óstio/túnel) e numa quarta categoria que agrupou todas as peritonites (somando-se as categorias peritonites e peritonites associadas a infecções de óstio/túnel), conforme mostra a tabela 32. As densidades de incidência 
foram comparadas pelo cálculo do escore Z, conforme demonstrado na tabela 33.

Tabela 31 - Análise dos fatores de risco em potencial nos pacientes que apresentaram e nos que não apresentaram episódios infecciosos, em relação à idade ao início da diálise, em anos (mediana, IQ 25-75), cirurgia abdominal prévia, diálise peritoneal prévia, presença de vazamentos pelo óstio, presença de derivações abdominais, uso de antibiótico profilático à passagem do cateter, tempo entre passagem do cateter e início da diálise, em dias (mediana e IQ 25-75) e porcentagem de pacientes com nível de albumina sérica $<3,5 \mathrm{~g} / \mathrm{dL}$

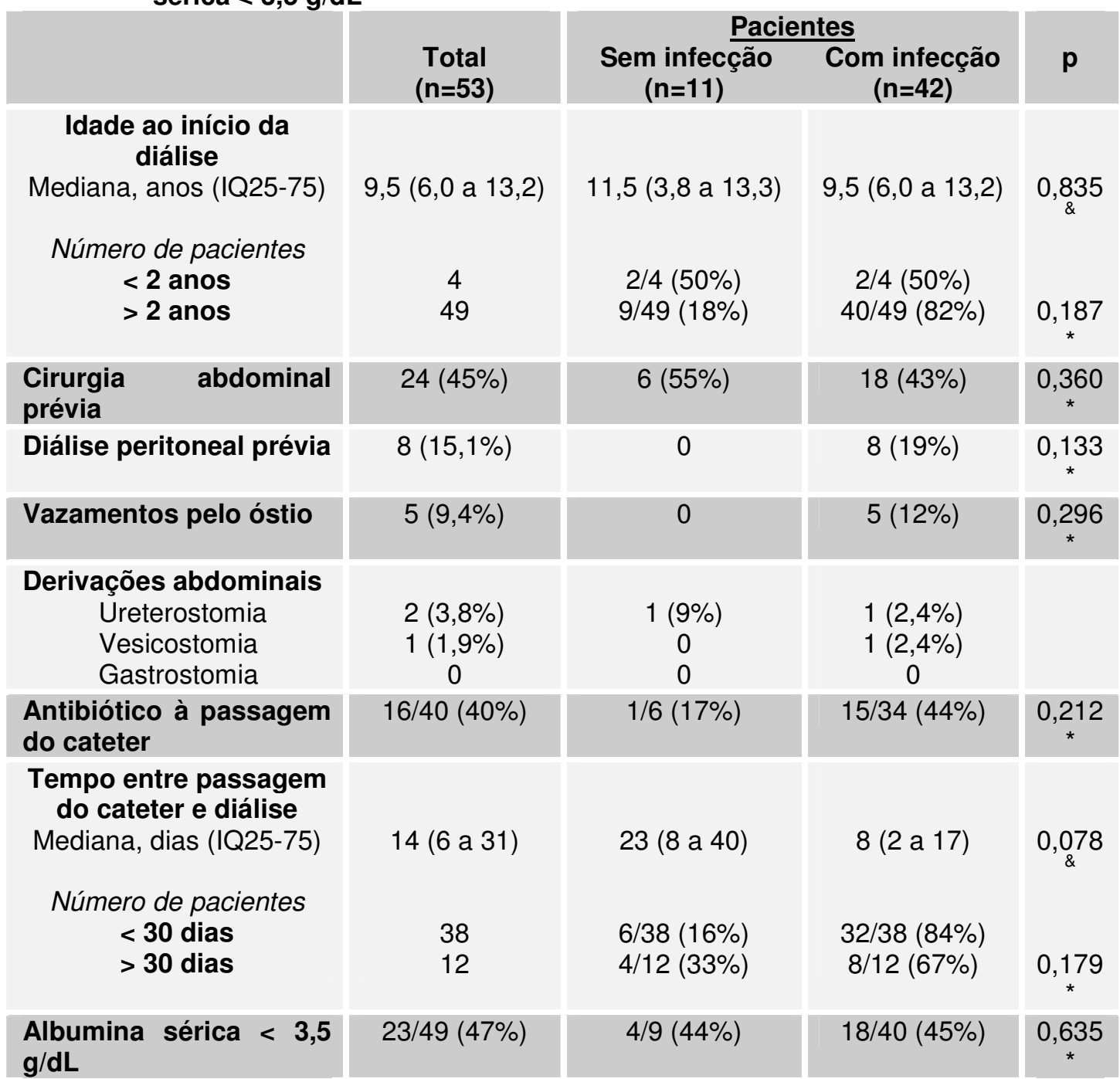

IQ25-75: intervalo interquartil 25\%-75\% \&valores de p para teste Mann-Whitney *valores de $p$ para teste exato de Fisher 
Tabela 32 - Cálculo da densidade de incidência de infecção (episódios/ pacientemês) em quatro categorias de infecção (óstio/túnel, peritonite, peritonite associada a infecção de óstio/túnel e em todas as peritonites) nas três modalidades de diálise (DPI, DPAC, DPA)

\begin{tabular}{|l|c|c|c|}
\hline & DPI & DPA & DPAC \\
\hline Óstio/túnel & 0,081 & 0,036 & 0,035 \\
\hline Ostio/túnel + Peritonite & 0 & 0,009 & 0,014 \\
\hline Peritonite & 0,072 & 0,047 & 0,047 \\
\hline Todas as peritonites & 0,072 & 0,056 & 0,062 \\
\hline
\end{tabular}

Tabela 33 - Comparação da densidade de incidência de infecção (episódios/ pacientemês) em quatro categorias de infecção (óstio/túnel, peritonite, peritonite associada a infecção de óstio/túnel e em todas as peritonites), nas 3 modalidades de diálise (DPI, DPAC, DPA), pelo cálculo do escore Z

\begin{tabular}{|l|c|c|c|}
\hline & $\begin{array}{c}\text { DPIxDPA } \\
\text { Escore } \mathbf{Z}(\mathbf{p})\end{array}$ & $\begin{array}{c}\text { DPIxDPAC } \\
\text { Escore } \mathbf{Z}(\mathbf{p})\end{array}$ & $\begin{array}{c}\text { DPAxDPAC } \\
\text { Escore } \mathbf{Z}(\mathbf{p})\end{array}$ \\
\hline Óstio/túnel & $0,45(0,326)$ & $0,48(0,316)$ & $0(0,5)$ \\
\hline Óstio/túnel + Peritonite & $0,60(0,274)$ & $0,53(0,298)$ & $0,18(0,428)$ \\
\hline Peritonite & $0,80(0,212)$ & $0,7(0,242)$ & $0(0,5)$ \\
\hline Todas as peritonites & $0,28(0,390)$ & $0,14(0,444)$ & $0(0,5)$ \\
\hline
\end{tabular}

\subsection{PERFIL DE SENSIBILIDADE DOS Staphylococcus sp A OXACILINA}

As tabelas 34 a 36 demonstram o perfil encontrado de sensibilidade dos Staphylococcus sp a oxacilina em toda a casuística. Não foi encontrado Staphylococcus sp resistente a vancomicina em nenhum caso.

Tabela 34 - Perfil de sensibilidade dos 68 Staphylococcus $s p$ isolados nas culturas de óstio e de líquido peritoneal

\begin{tabular}{|l|c|}
\hline Sensibilidade dos Staphylococcus sp a oxacilina & $\begin{array}{c}\text { No culturas (\%) } \\
(\mathbf{n}=68)\end{array}$ \\
\hline Sensível & $51(75 \%)$ \\
\hline Resitente & $17(25 \%)$ \\
\hline
\end{tabular}

Tabela 35 - Perfil de sensibilidade dos 45 Staphylococcus aureus isolados nas culturas de óstio e de líquido peritoneal

\begin{tabular}{|l|c|}
\hline Sensibilidade dos S. aureus a oxacilina & $\begin{array}{c}\text { № culturas (\%) } \\
(\mathbf{n}=\mathbf{4 5})\end{array}$ \\
\hline Sensível & $40(89 \%)$ \\
\hline Resitente & $5(11 \%)$ \\
\hline
\end{tabular}


Tabela 36 - Perfil de sensibilidade dos 23 Staphylococcus coagulase negativo isolados nas culturas de óstio e de líquido peritoneal

Sensibilidade dos Staphylococcus coagulase negativo a № culturas (\%) oxacilina

Sensível $11(48 \%)$

Resistente $12(52 \%)$

O gráfico 12 descreve o perfil de sensibilidade dos Staphylococcus sp a oxacilina ao longo do período avaliado (1994 a 2005).

Gráfico 12 - Perfil de sensibilidade à oxacilina dos S. aureus e Staphylococcus coagulase negativo (S. coag-) isolados nas culturas de óstio e de líquido peritoneal ao longo do período avaliado (1994-2005)

Perfil de sensibilidade dos Staphylococcus sp ao longo dos anos

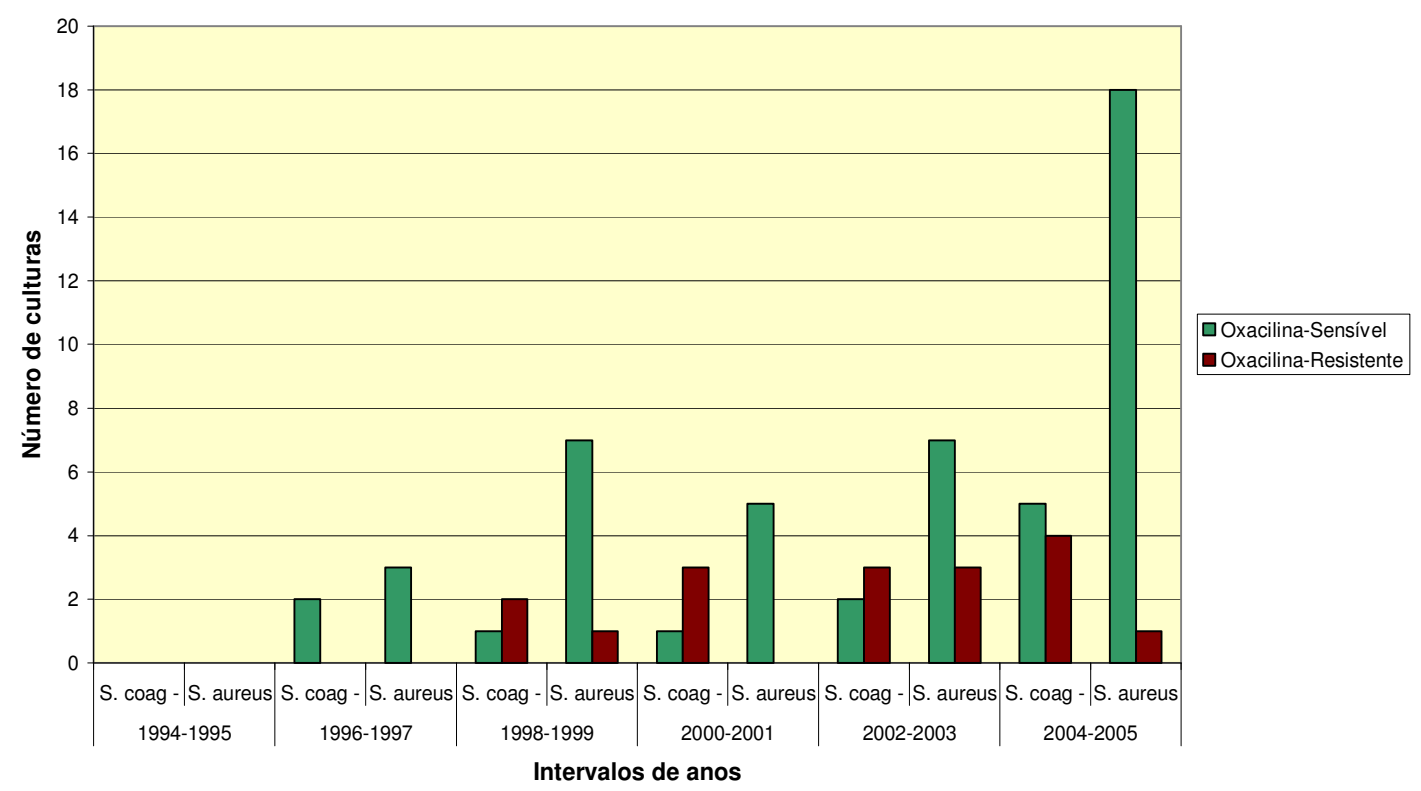




\section{Discussão}




\section{DISCUSSÃO}

A análise dos dados demográficos dos nossos pacientes revela que malformações urológicas constituem a principal causa primária de DRC, o que é compatível com as demais casuísticas pediátricas.

Segundo o Registro Italiano, displasia e hipoplasia renal são as principais causas de DRC nesta população, em $24 \%$ dos pacientes, seguida por glomerulopatias primárias, em 19,7\%. Somando-se as categorias displasia e hipoplasia renal, uropatias obstrutivas e nefropatia do refluxo, 43,5\% dos pacientes apresentam DRC secundária a malformações nefrourológicas (Verrina et al., 2004). De acordo com o NAPRTCS, malformações nefro-urológicas são também a principal causa de DRC, em 30,1\% dos pacientes, assim como no Registro Pediátrico Japonês, em 35,8\% dos pacientes e segundo o USRDS, em 52\% dos pacientes (Neu et al., 2002; Alexander et al., 2004).

A predominância de pacientes do sexo masculino em nossa casuística deve-se, provavelmente, à predominância de malformações urológicas, uma vez que estas são mais freqüentes em crianças do sexo masculino.

A mediana de idade ao ingresso no programa de diálise crônica dos nossos pacientes foi de $9,5(0,3$ a 18,2$)$ meses. Esse dado é variável nas casuísticas citadas na literatura. Dados do USRDS de 2001 revelam que a idade média ao início da diálise nos EUA é de 12,0 anos (USRDS 2003). Na 
Itália, a idade média ao ingresso no programa de diálise peritoneal é de 7,7 anos (Verrina et al., 2004).

A maioria dos pacientes (40\%) realizou primeiramente DPI e, após, DPA. Uma parcela grande dos pacientes (23\%) realizou apenas DPA, principalmente nos últimos anos. Isso se deve à tendência atual, em nossa unidade, de realizar o treinamento dos pacientes em insuficiência renal prédialítica em regime ambulatorial e, ao final do treinamento, realizar internação eletiva para implante do cateter de Tenckhoff e início de diálise domiciliar em duas semanas. Reserva-se, atualmente, a DPI para pacientes nos quais não houve tempo hábil para colocação ambulatorial do cateter e para aqueles cujas condições sócio-econômicas e habitacionais contraindiquem a diálise domiciliar. Podemos notar que poucos pacientes dessa casuística realizaram DPAC. Isso se explica porque a maior parte dos pacientes cujos prontuários não estavam disponíveis para análise estiveram em programa de diálise no período inicial do estudo (1994 a 2000), época em que era realizada DPAC.

Segundo o relato do NAPRTCS de 2006, DPA é a modalidade de DP mais utilizada na população pediátrica, sendo que 1 mês após de ingresso no programa de diálise peritoneal $67,7 \%$ dos pacientes realizavam DPA, $20,8 \%$ realizavam DPAC e 6,8\% DPI; 36 meses após ingresso em programa dialítico, $71,3 \%$ encontravam-se em DPA, 15,2\% realizavam DPAC e $4 \%$ DPI (NAPRTCS, 2006).

A maior parte dos nossos pacientes (49\%) saiu do programa de diálise crônica devido à realização de transplante renal. A segunda maior 
causa de saída do programa foi transferência para hemodiálise $(18,9 \%)$, em todos os casos após episódio de peritonite. Apenas um paciente foi transferido para o setor de diálise de adultos, o que acontece, no Instituto da Criança, após o paciente completar 20 anos de idade. Não houve nenhum óbito secundário a peritonite ou infecção relacionada a cateter de diálise peritoneal. Houve apenas um óbito em nossa casuística, no período avaliado, por causa não relacionada à diálise.

Dados do NAPRTCS demonstram como principais causas de saída do programa de diálise, realização de transplante renal (65\%) e transferência para hemodiálise (22\%). As principais razões para transferência para hemodiálise nessa casuística foram infecção (28\%) e preferência da família (23\%) (NAPRTCS, 2006).

A análise dos dados de peso e estatura ao início do programa de diálise revela que nossos pacientes apresentam comprometimento de estatura e peso, o que é esperado numa população de crianças portadoras de DRC (Mehls et al., 2004; NAPRTCS, 2006). Observa-se que os pacientes apresentavam comprometimento proporcionado de peso e estatura, refletido pelo escore Z de IMC/idade conservado.

Não observamos diferença estatisticamente significante entre o escore $Z$ de estatura/idade, peso/idade e IMC/idade ao início e ao final do programa de diálise. A permanência no programa de diálise peritoneal crônica parece não ter modificado os parâmetros pôndero-estaturais dos pacientes em relação aos índices iniciais. De fato, o tratamento dialítico parece não melhorar as taxas de crescimento dos pacientes pediátricos, 
tanto em diálise peritoneal quanto em hemodiálise (Kleinlnecht et al., 1980; Mehls et al., 2004). Em algumas casuísticas observou-se até um gradual decréscimo no escore $Z$ de estatura de pacientes em programa de diálise peritoneal por tempo prolongado (von Lilien et al., 1989).

A análise dos episódios infecciosos revela elevada densidade de incidência de peritonites e infecções relacionadas ao cateter de diálise peritoneal em nossa casuística. Houve 0,49 infecções de óstio/ paciente-ano e 0,71 peritonites/ paciente-ano, somando os grupos peritonites $(0,59)$ e peritonites associadas à infecção de óstio e túnel $(0,12)$. Nossas taxas se assemelham às de outros centros. Segundo o mais recente relatório do NAPRTCS, a densidade de incidência de peritonite nessa população foi de 0,71 peritonites/ paciente-ano (NAPRTCS, 2006). Entretanto, nossas taxas de infecção estão bem acima das citadas em outras casuísticas na literatura. As menores taxas de peritonites e infecções de óstio e túnel do cateter de diálise peritoneal são as encontradas no Japão. Segundo o Registro Japonês, houve 0,17 peritonites/ paciente-ano e 0,29 infecções de óstio e túnel/ paciente-ano nesta população, entre 1999 e 2003 (Hoshii et al., 2006). As baixas taxas de infecção na população japonesa são atribuídas, em parte, ao programa de treinamento oferecido aos pacientes e familiares. São realizadas sessões de treinamento prolongadas, por 6 a 7 semanas, caracterizados pela repetição e compreensão dos princípios e técnicas da DP (Hoshii et al., 2006).

Auron et al. (2007) citam queda das taxas de peritonite em sua unidade de diálise peritoneal pediátrica de 0,56 peritonites / paciente-ano 
entre os anos de 1997 e 2004 para 0,19 peritonites/ paciente-ano entre os anos de 2001 e 2004, quando foram introduzidas várias medidas preventivas de forma sistematizada. Essas medidas incluíam uso de cateteres de Tenckhoff com duplo "cuff", uso de cefalosporina de primeira geração profilaticamente à implantação do cateter, uso de cola de fibrina se o cateter fosse utilizado antes de 3 dias após sua implantação, rastreamento para pacientes com colonização nasal por $S$. aureus e uso de mupirocina intranasal ou tópica, profilaticamente no óstio do cateter, nos casos com secreção nasal positiva.

Em nossa casuística, não pudemos avaliar a associação dos episódios infecciosos estudados com os fatores de risco classicamente citados na literatura pertinente.

A mediana de idade ao início da diálise foi maior no grupo sem infecção do que no grupo com infecção, mas essa diferença não foi estatisticamente significante. Quando os pacientes foram separados em 2 grupos (menores e maiores de 2 anos), também não foi encontrada associação estatisticamente significante entre a faixa etária e infecção. $\mathrm{Na}$ maior parte das casuísticas citadas na literatura, as taxas de peritonites e infecções relacionadas a cateter de DP são inversamente proporcionais à idade (Rahim et al., 2004; Warady et al., 2004; Bohem et al., 2005; NAPRTCS, 2006).

Em nossa casuística, vazamentos pelo óstio e diálise peritoneal prévia ocorreram somente no grupo de pacientes com infecção. Entretanto, essa diferença não foi estatisticamente significante, provavelmente devido ao 
pequeno número de pacientes analisados que apresentaram este problema. Na casuística de Rhaim et al. (2004), que analisaram os fatores de risco para complicações relacionadas ao cateter de DP, em 90 crianças em DP crônica entre 1990 e 2000, destacou-se como fator de risco para infecção relacionada a cateter, a ocorrência de diálise peritoneal prévia. Entretanto, não foi demonstrada associação entre vazamentos pelo óstio infecção, contrariamente ao observado em estudos anteriores, onde a presença de vazamentos constituiu risco não só para peritonite como também para infecções de túnel de cateter (Gokal et al., 1998).

Em nossa casuística, não houve associação entre história de cirurgia abdominal prévia e infecção. Rahim et al. (2004) também não observaram associação entre cirurgia abdominal prévia e infecção ou complicações nãoinfecciosas relacionadas ao cateter.

Poucos dos nossos pacientes apresentaram derivações abdominais (apenas 2 ureterostomias e 1 vesicostomia), dificultando sua análise como fator de risco na nossa população. Em outros estudos, derivações abdominais (gastrostomia, vesicostomia e ureterostomia) foram fatores de risco para peritonites e infecções relacionadas a cateter (Rhaim et al., 2004; Warady et al., 2004).

Não foi possível demonstrar, em nossos pacientes, o uso de antibiótico profilático à passagem do cateter como fator de proteção para infecção. Entretanto, sua análise foi prejudicada porque muitos desses dados não foram resgatados dos prontuários, sendo pequeno o número de pacientes comparados. Múltiplos trabalhos têm mostrado que o uso de 
antibiótico profilático à passagem do cateter pode reduzir o risco de peritonite, mas não o de infecções relacionadas a cateter (Sardegna et al., 1998; Thodis et al, 2001; Strippoli et al., 2004).

Em nossa casuística, a mediana do tempo entre a passagem do cateter e o início da diálise apesar de menor no grupo de pacientes com infecção, não se mostrou estatisticamente significante como fator de risco para infecção, mesmo quando os pacientes foram categorizados entre aqueles que iniciaram diálise antes e após 30 dias da passagem do cateter. Segundo a casuística de Rahim et al. (2004), o tempo entre passagem de cateter e início da diálise inferior 14 dias foi associado a aumento de risco para vazamentos, mas não para infecção.

Hipoalbuminemia não foi fator associado a infecção em nossa casuística, o que também já foi citado em outras séries (Rahim et al., 2004; Bohem et al., 2005).

Em nossa análise, não foi observada diferença estatisticamente significante entre as densidades de incidência de infecções nas diferentes modalidades de diálise. Nossas taxas de infecção em DPI parecem ser maiores do que em DPA e DPAC, mas, provavelmente devido ao pequeno número de pacientes, essa diferença não foi estatisticamente significante. Há dados na literatura que sugerem um pequeno decréscimo das taxas de infecção de pacientes em DPA quando comparados com DPAC (Edefonti et al., 1996; NAPRTCS, 2003).

Outros fatores de risco citados na literatura pertinente, como características do cateter e baixa função renal residual não foram avaliados 
em nosso estudo. Em nossa unidade de diálise rotineiramente foram utilizados cateteres de duplo "cuff", impossibilitando a comparação com uso de cateteres com "cuff" único. Função renal residual é um dado cujo registro tem constado apenas nos prontuários mais recentes do período de coleta de dados, o que dificultou sua análise.

Os agentes etiológicos mais freqüentemente isolados em nossa casuística foram os gram-positivos. O perfil dos agentes encontrados nos casos de infecção de aquisição hospitalar foi muito próximo ao dos encontrados na casuística como um todo. Staphylococcus aureus e Staphylococcus coagulase negativo foram responsáveis por $57 \%$ das infecções de óstio e túnel do cateter e $51 \%$ das peritonites. Nos casos de peritonite associada à infecção de óstio, esses 2 agentes foram isolados em $89 \%$ das culturas de secreção de óstio e em $40 \%$ das culturas de líquido peritoneal. Esse dado também é encontrado em casuísticas de pacientes adultos (Bunke et al., 1997; Barretti et al., 2007) e na maioria das casuísticas pediátricas citadas na literatura. Segundo o Registro Pediátrico Japonês, $S$. aureus foi isolado em $79 \%$ das infecções de óstio e túnel do cateter e em $52 \%$ das peritonites (Hoshii et al., 2006). Segundo o NAPRTCS, entre os anos de 1992 e 1997, os agentes gram-positivos foram isolados em 48,7\% dos episódios de peritonites, os gram-negativos em $21,6 \%$ e os fungos em $1,8 \%$ dos casos. (Furth et al., 2000).

Warady et al. (2007) em recente estudo baseado no registro IPPR ("International Pediatric Peritonitis Registry"), com dados coletados de 47 centros pediátricos em 14 países, no período 2001 a 2004, compreendendo 
491 episódios de peritonites bacterianas, relatam predominância de agentes gram-positivos (44\%), seguida por gram-negativos (25\%), com obtenção de cultura negativa em $31 \%$ dos casos. Staphylococcus sp foram os agentes mais encontrados, sendo Staphylococcus coagulase negativo o mais comum (24\%), seguido por S. aureus (22\%).

Barretti et al. (2007) em recente compilação de estudos latinoamericanos, dentre os quais, trabalhos brasileiros em população adulta, sobre peritonites em diálise peritoneal, citam Staphylococcus aureus como o principal agente até os meados dos anos 90, com uma participação crescente, nos anos mais recentes, de Staphylococcus coagulase negativos e agentes gram-negativos. Dentre estes trabalhos, Pecoits-Filho et al. relatam que, entre 1980 e 1995, o agente etiológico mais isolado, na unidade de DPAC do Hospital Universitário Evangélico de Curitiba-PR foi S. aureus, enquanto que, entre 1999 e 2003, predominou o isolamento de Staphylococcus epidermidis seguido por $S$. aureus e gram-negativos (Pecoits-Filho et al., 1998; Silva et al., 2004). Lima et al. (2007) evidenciaram, na Unidade de Diálise da Universidade Federal do Rio de Janeiro, entre 2000 e 2005, a predominância de Staphylococcus coagulase negativo (24,2\%), seguido por enterobactérias $(17,9 \%)$ e S. aureus $(8,4 \%)$.

Em nossa casuística, $52 \%$ dos Staphylococcus coagulase negativo e $11 \%$ dos $S$. aureus mostraram-se resistentes a oxacilina. Esse perfil de sensibilidade dos Staphylococcus $s p$ é semelhante ao encontrado na literatura de diálise peritoneal pediátrica. Segundo o IPPR, entre 2001 e 
2004, 50\% dos Staphylococcus coagulase negativo e $14 \%$ dos S. aureus encontrados foram oxacilina - resistentes (Warady et al., 2007).

Os agentes etiológicos mais associados a complicações, em nossa casuística, foram Candida sp, Staphylococcus sp, Pseudomonas aeruginosa, Corynebacterium e Acinetobacter baumanii.

Em relação à perda funcional peritoneal, agrupamos os agentes bacterianos encontrados nos casos afetados em gram-positivos e gramnegativos, e observamos que, embora houvesse uma tendência a maior freqüência desta complicação nas infecções por gram-negativos, essa diferença não foi estatisticamente significativa.

Pseudomonas aeruginosa, Corynebacterium, S. aureus e Staphylococcus coagulase negativo foram os agentes que se associaram com mais freqüência à colonização do óstio do cateter. Não se demonstrou, no entanto, diferença quanto ao risco de colonização, nem na comparação destes agentes entre si, nem após agrupamento destes agentes em grampositivos e gram-negativos.

Analisando, nos três grupos de infecção, o risco para necessidade de retirada do cateter de acordo com agente etiológico e agrupando os agentes bacterianos isolados em gram-positivos e gram-negativos, demonstrou-se associação estatisticamente significante entre retirada do cateter e infecção por agentes gram-negativos.

Quando avaliamos a necessidade de retirada de cateter de acordo com o grupo de infecção, apesar de porcentualmente ocorrer maior número de retiradas de cateter nas peritonites em relação às infecções de óstio, não 
houve diferença estatisticamente significante entre os grupos de infecção analisados quanto a esta complicação.

Candida sp e Pseudomonas aeruginosa, apesar de isolados em pequeno número de culturas, mostraram alto índice de complicações. Candida $s p$ foi isolada apenas em três episódios de peritonite, mas em $3 / 3$ (100\%) dos casos houve necessidade de retirada do cateter, e em 2/3 (67\%), evolução para perda funcional peritoneal. Pseudomonas aeruginosa foi encontrada em 9 episódios infecciosos. Em 56\% desses casos foi necessária a retirada do cateter. Houve perda funcional em 1/2 (50\%) dos episódios de peritonite em esse agente foi isolado.

Esses agentes também são citados na literatura como mais relacionados a complicações. Kuizon et al. (1995) relatam, em população dialítica pediátrica, que $S$. aureus, Pseudomonas e fungos foram responsáveis por $50 \%$ dos episódios de peritonite e infecção de óstio em que houve necessidade de troca do cateter. Segundo o Registro Pediátrico Japonês, houve necessidade de retirada do cateter em todos os 5 casos de peritonite fúngica observados. Em $78 \%$ das peritonites causadas por $S$. aureus resistentes a oxacilina foi necessária retirada do cateter, enquanto que em apenas $17 \%$ dos episódios causados por outros gram-positivos ela foi necessária (Hoshii et al., 2006).

O nosso percentual de culturas negativas foi de $13 \%$ nas culturas de secreção de óstio nos casos de infecção de óstio/túnel e 25\% nas culturas de líquido peritoneal nos casos de peritonite, o que é compatível com o encontrado na literatura. Segundo dados do Registro Pediátrico Japonês, 
13\% das culturas foram negativas nos episódios de infecção de óstio e 14,3\%, nas peritonites (Hoshii et al., 2006). Segundo o IPPR, o percentual de culturas negativas nos episódios de peritonite foi de $31 \%$ (Warady et al., 2007).

Em nossa casuística, chama a atenção o alto percentual de culturas negativas nos episódios de peritonite associada à infecção de óstio (31\% das culturas de secreção de óstio e $62 \%$ das culturas de líquido peritoneal). Não pudemos identificar a causa dessa observação.

Observamos um número muito reduzido de casos em que houve falha terapêutica com o uso de antibiótico empírico baseado em nosso protocolo, até resultado de culturas. Na maior parte dos casos em que o antibiótico inicial foi trocado, essa troca foi realizada para término de antibioticoterapia por via oral ou para realizar descalonamento após resultado de antibiograma (por exemplo, quando o paciente recebeu inicialmente ceftriaxone, mas foi isolado agente sensível a cefalotina, sendo trocado ceftriaxone por cefalotina).

Nota-se que a maioria dos pacientes com peritonite foi internada para tratamento, devido à gravidade do quadro clínico. É norma da nossa unidade a administração de antibioticoterapia parenteral para tratamento de todos os episódios de peritonite e internação nos casos mais graves. Nos casos em que o paciente se encontra em bom estado geral, o tratamento é realizado com medicação parenteral em regime de leito-dia. Já a maioria dos casos de infecção de óstio foi tratada no domicilio, com medicações por via oral. 
A técnica de selo de antibiótico é convencionalmente utilizada em cateteres vasculares. Há vários estudos mostrando que ela constitui uma opção de tratamento em infecções relacionadas a cateteres venosos centrais de longa permanência, geralmente utilizados para hemodiálise, nutrição parenteral ou quimioterapia, em pacientes com dificuldade de acesso venoso (Bagnall-Reeb, 2004; Paglialonga et al., 2004). As taxas de sucesso são variáveis, dependendo do agente etiológico envolvido (Poole et al., 2004). Antibioticoterapia sistêmica associada geralmente é necessária. Existem também relatos sobre a utilização de selo de antibiótico em cateteres de diálise peritoneal, inclusive em casos de peritonite fúngica (Lee et al., 1995).

Na Unidade de Diálise Peritoneal do ICr - HCFMUSP, o selo de antibiótico tem sido utilizado em associação à antibioticoterapia parenteral nos casos de peritonite em que o paciente mantém cultura positiva no líquido peritoneal, mas sem sinais de infecção sistêmica, com melhora dos sintomas e da celularidade do líquido peritoneal.

Em nossa experiência, a utilização do selo de antibiótico se mostrou uma alternativa eficaz na tentativa de evitar a troca do cateter de diálise peritoneal em 8/10 (80\%) das infecções por Staphylococcus sp e em 2/3 (67\%) das infecções por gram-negativos. Entretanto, observou-se que, nos casos de peritonite fúngica, o selo de antibiótico não foi eficaz, em nenhum caso, para evitar a retirada do cateter.

Em conclusão, consideramos que, apesar de comparáveis aos resultados encontrados em centros norte-americanos e em alguns centros 
europeus, nossas taxas de peritonites e de infecções de óstio e túnel de cateter devem ser consideradas elevadas, visto que estão bem acima das menores taxas citadas na literatura.

Staphylococcus $s p$ foram os agentes mais isolados nos três tipos de infecção estudados, entretanto não se demonstrou associação estatisticamente significativa de risco de retirada de cateter ou perda funcional peritoneal relacionada a estes agentes bacterianos Medidas profiláticas no sentido de diminuir a contaminação por esses agentes podem constituir uma intervenção eficaz para a redução das taxas de infecção diálise-relacionada e sua morbidade. Como as infecções causadas por Staphyloccocus sp estão associadas à colonização da pele por estes agentes, tanto a ênfase no treinamento cuidadoso e contínuo dos responsáveis pela instalação domiciliar da diálise, no sentido de melhorar a lavagem de mãos e os cuidados no momento da conexão do cateter, como a utilização de mupirocina para uso tópico nasal, nos que apresentarem colonização local com Staphylococcus sp, podem se constituir em importante medida para prevenção da infecção por este grupo de agentes (Piraino, 2004; Warady et al., 2004; Russo et al., 2006).

Acreditamos que o presente estudo tenha sido importante para a avaliação das taxas de infecção na Unidade de Diálise Peritoneal do Instituto da Criança do HC FMUSP desde o início do programa de diálise peritoneal crônica até o momento. Pelo fato de tratar-se de um estudo retrospectivo, baseado em registros de prontuários, encontramos limitações, principalmente quanto à qualidade do preenchimento dos prontuários e à 
dificuldade de acesso aos mesmos. Dados importantes dos primeiros anos em que foi iniciado o programa de diálise crônica no $\mathrm{ICr}$ foram perdidos. Também não foram resgatados alguns dados relevantes para nossa análise, porque não constavam nos registros dos prontuários. Mesmo com essas limitações, acreditamos que esse estudo tenha sido útil na construção de uma coorte histórica para comparação com resultados de intervenções futuras. Estudos prospectivos para avaliação de potenciais fatores de risco associados a peritonites e infecções relacionadas a cateter e estudos comparando intervenções específicas para a diminuição das taxas de infecção são necessários.

A diminuição da taxa de infecções em diálise peritoneal apresenta efeitos benéficos imediatos e mediatos, promovendo em curto prazo, redução da morbi-mortalidade relacionada ao processo infeccioso propriamente dito, e em longo prazo, favorecendo preservação da integridade peritoneal, com maior chance de manutenção de euvolemia por esta metodologia de terapia de substituição renal, atenuação do processo inflamatório associado à terapia dialítica, assim como da instalação da Síndrome "MIA", com potencial favorecimento da redução da mortalidade cardiovascular do paciente. 
Conclusões 


\section{CONCLUSÕES}

1. Nossas taxas de peritonite e infecção de óstio e túnel do cateter são elevadas. Elas são comparáveis às citadas em outros centros, mas estão bem acima das menores taxas citadas na literatura.

2. Staphylococcus $s p$ foram os agentes mais isolados em todas as categorias analisadas de infecção

3. Demonstrou-se, em nossa análise, associação estatisticamente significante entre necessidade de retirada do cateter de diálise e infecção por agentes gram-negativos.

4. Candida sp e Pseudomonas aeruginosa, apesar de isolados em pequeno número de culturas, mostraram alto índice de complicações. Em 3/3 (100\%) das peritonites por Candida $s p$ houve necessidade de retirada do cateter, e em 2/3 (67\%), evolução para perda funcional peritoneal. Pseudomonas aeruginosa foi encontrada em 9 episódios infecciosos. Em $56 \%$ desses casos foi necessária a retirada do cateter. Houve perda funcional em 1/2 (50\%) dos episódios de peritonite em esse agente foi isolado.

5. Não pudemos avaliar, em nossa casuística, a associação entre os fatores de risco estudados e infecção, devido ao reduzido número de pacientes não acometidos por infecção. 


\section{Referências Bibliográficas}




\section{REFERÊNCIAS BIBLIOGRÁFICAS}

1. Abensur H, Guersoni, AC. Diálise peritoneal. In: Toporovski J, Mello VR, Martini Filho D, Benini V, Andrade VBO. Nefrologia Pediátrica. $2^{\mathrm{a}}$ ed. Rio de Janeiro: Guanabara Koogan; 2006. p. 589-600.

2. Alexander SR, Warady BA. The demographics of dialysis in children. In: Warady BA, Schaefer FS, Fine RN, Alexander SR. Pediatric Dialysis. Great Britain: Kluwer Academic Publishers; 2004. p.35-46.

3. Auron A, Simon S, Andrews W, Jones L, Shirley J, Musharaf G, Warady BA. Prevention of peritonitis in children receiving peritoneal dialysis. Pediatr Nephrol. 2007;22: 578-85.

4. Bagnall-Reeb H. Evidence for the Use of the Antibiotic Lock Technique. J Infus Nurs. 2004; 27(2): 118-22.

5. Balfe JW, Vigneaux A, Williamson J, Hardy BE. The use of CAPD in the treatment of children with end-stage renal disease. Perit Dial Bull. $1981 ; 1: 35-8$.

6. Barreti P, Bastos KA, Dominguez J, Caramori JC. Peritonitis in Latin America. Perit Dial Int. 2007; 27 (3): 332-9.

7. Benfield MR, McDonald R, Sullivan EK, Stablein DM, Tejani A. The 1997 annual renal transplantation in children: Report of the North American Pediatric Renal Transplant Cooperative Study (NAPRTCS). Pediatr Transplant. 1999; 2:152-67.

8. Blackfan KD, Maxcy KF. The intraperitoneal injection of saline solution. Am J Dis Child. 1918; 15: 19-28. 
9. Boehm M, Vécsei A, Aufricht C, Mueller T, Csaicsich D, Arbeiter K. Risk factors for peritonitis in pediatric peritoneal dialysis: a singlecenter study. Pediatr Nephrol. 2005; 20:1478-83.

10. Bouts AHM, Davin JC. Immune function of children on dialysis. In: Warady BA, Schaefer FS, Fine RN, Alexander SR. Pediatric Dialysis. Great Britain: Kluwer Academic Publishers; 2004. p.369-82.

11. Brandt ML, Brewer ED. Peritoneal dialysis access in children. In: Warady BA, Schaefer FS, Fine RN, Alexander SR. Pediatric Dialysis. Great Britain: Kluwer Academic Publishers; 2004. p.83-90.

12. Bunke CM, Brier ME, Golper TA. Outcomes of single organism peritonitis in peritoneal dialysis: gram negative versus gram positives in the network 9 peritonitis study. Kidney Int. 1997; 52:524-9.

13. Diaz-Buxo JA. Clinical use of peritoneal dialysis. In: Nissenson AR, Fine RN. Dialysis therapy. 4ª ed. McGrow-Hill; 2005. p. 421-89.

14. Edefonti A, Consalvo G, Pappalettera M. Infectious complications in pediatric patients treated with chronic peritoneal dialysis. Perit Dial Int. 1996;16 (Suppl1):S543-7.

15. Faller B. Amino acid-based peritoneal dialysis solutions. Kidney Int. 1996; 56 (suppl): 81-5.

16. Fukui M, Maeda K, Sakamoto K, Hamada C, Tomino Y. Laparoscopic manipulation for outflow failure of peritoneal dialysis catheter. Nephron. 1999; 83:369.

17. Furth SL, Donaldson LA, Sullivan EK, Watkins SL. Peritoneal dialysis catheter infections and peritonitis in children: a report of the North 
American Pediatric Renal Transplant Cooperative Study. Pediatr Nephrol. 2000; 15:179-82.

18. Gokal R, Alexander S, Ash S, Chen TW, Danielson A, Holmes C, Joffe P, Moncrief J, Nichols K, Piraino B, Prowant B, Slingeneyer A, Stegmayr B, Twardowiski Z, Vas S. Peritoneal catheters and exit-site practices toward optimum peritoneal access: 1998 update. (Official report from the International Society for Peritoneal Dialysis). Perit Dial Int. 1998; 18:11-33.

19. Goodman WG, Goldin J, Kuizon BD, Yoon C, Gales B, Sider D, Wang Y, Chung J, Emerick A, Greaser L, Elashoff RM, Salusky IB. Coronary-artery calcification in young adults with endstage renal disease who are undergoing dialysis. N Engl J Med. 2000; 342:147883.

20. Harvey EA. Non-infectious complications of peritoneal dialysis and hemodialysis. In: Warady BA, Schaefer FS, Fine RN, Alexander SR. Pediatric Dialysis. Great Britain: Kluwer Academic Publishers. 2004; p.415-41.

21. Holmes, CJ. Abnormalities of Host Defense Mechanisms During Peritoneal Dialysis. In: Nissenson AR, Fine RN. Dialysis therapy. 3를 ed. Philadelphia: Hanley \& Belfus; 2002. p.235-9.

22. Holtta TM, Ronnholm KA, Jalanko H, Ala-Houhala M, Antikainen M, Holmberg C. Peritoneal dialysis in children under 5 years of age. Perit Dial Int. 1997; 17(6): 573-80. 
23. Horan, TC. How to compare SSI rates using aggregated data from NNIS System. In: SHEA Conference, Atlanta, USA, 1993, NR94.

24. Hoshii S, Wada N, Honda M, Japanese Study Group of Pediatric Peritoneal Dialysis. A survey of peritonitis and exit-site and/or tunnel infections in Japanese children on PD. Pediatr Nephrol. 2006; 21:82834.

25. Imholz ALT, Lameire N, Faict D, Koomen GC, Krediet RT, Martis L. Evaluation of short-chain polypeptides as an osmotic agent in continuous ambulatory peritoneal dialysis patients. Perit Dial Int. 1994; 14: $215-22$.

26. KDOQI - National Kidney Foundation Kidney Disease Outcomes Quality Initiative - NKF KDOQI. Clinical Practice Guidelines. Available from: http:// www.kidney.org/professionals/kdoqi.

27. Kleinknecht C, Broyer M, Gagnadoux M, Marti-Henneberg C, Dartois A, Kermanach C. Growth in children treated with long-term dialysis. A study of 76 patients. Adv Nephrol. 1980; 9:133-66.

28. Kuizon B, Melocoton TL, Holoway M, Ingles S, Jing H, Fonkalsrud W, Salusky IB. Infectious and catheter-related complications in pediatric patients treated with peritoneal dialysis at a single institution. Pediatr Nephrol. 1995; 9:S12-7.

29. Lee SH, Chiang SS, Hseih SJ, Shen HM. Successful treatment of fungal peritonitis with intracatheter antifungal retention. Adv Perit Dial. $1995 ; 11: 172-5$. 
30. Lima RC, Barreira $A$, Cardoso $F L$, Lima $M H$, Leite Junior $M$. Ciprofloxacin and cefazolin as a combination for empirical initial therapy of peritoneal dialysis-related peritonitis: five-year follow-up. Perit Dial Int 2007; 27:56-60.

31. Maxwell M, Rockey R, Kleeman C. Peritoneal Dialysis. J Am Med Assoc, 1995, 170: 917-24.

32. Mehls O, Schaefer FS, Tönshoff B. Growth disturbance in chronic renal failure: etiology and treatment. In: Warady BA, Schaefer FS, Fine RN, Alexander SR. Pediatric Dialysis. Great Britain: Kluwer Academic Publishers; 2004. p.259-78.

33. Meneses RP, Sylvestre LC, Ribeiro DS. Peritonites em centro pediátrico-série de 5 anos. Apresentado ao XXIII Congresso Brasileiro de Nefrologia; 2006; Gramado, RS.

34. Millar DJ, Holmes C, Faict D, Dawnay A. Comparison of in vitro AGE formation between standard PD fluid and a novel bicarbonate/lactate formulation. Perit Dial Int. 1998; 18:74-82.

35. Nakayama M, Kawaguchi Y, Yamada K, Hasegawa T, Takazoe $\mathrm{K}$, Katoh $\mathrm{N}$ et al. Immunohistochemical detection of advanced glycosylation end-products in the peritoneum and its possible pathophysiological role in CAPD. Kidney Int. 1997; 51:182-6.

36. NAPRTCS - North American Pediatric Renal Transplant Cooperative Study. Available from: http://www.naprtcs.org.

37. National Center for Health Statistcs, CDC 2000. Available from: http://www.cdc.gov/nchs. 
38. Neu AM, Ho PL, McDonald RA, Warady BA. Chronic dialysis in children and adolescents. The 2001 NAPRTCS Annual Report. Pediatr Nephrol. 2002; 17:656-63.

39. Offner G, Latta K, Hoyer PF, Baum HJ, Ehrich JH, Pichlmayr R, Brodehl J. Kidney transplanted children come of age. Kidney Int. 1999; $55: 1509-17$.

40. Paglialonga F, Esposito S, Edefonti A, Principi N. Catheter-related infections in children treated with hemodialysis. Pediatr Nephrol. 2004; 19(12): 1324-33.

41. Paniagua R, Amato D, Vonesh E, Correa-Rotter R, Ramos A, Moran J, Mujais S, for the Mexican Nephrology Collaborative Study Group. Effects of increased peritoneal clearances on mortality rates in peritoneal dialysis: ADEMEX, a prospective, randomized, controlled trial. J Am Soc Nephrol. 2002; 13: 1307-20.

42. Pecoits-Filho R, Lindholm B, Stenvinkel P. The malnutrition, inflammation and atherosclerosis (MIA) syndrome - the heart of the matter. Nephrol Dial Transpant. 2002; 17 (suppl 11): 28-31.

43. Pecoits-Filho RFS, Pasqual DD, Fuerbringer R, Sauthier SM, Riella MC. Diálise peritoneal contínua ambulatorial (DPCA): experiência de 15 anos em Curitiba. Jornal Brasileiro Nefrologia. 1998; 20: 22-30.

44. Piraino B. New insights on preventing and managing peritonitis. Pediatr Nephrol. 2004; 19:125-7. 
45. Poole CV, Carlton D, Bimbo L, Allon M. Treatment of catheter-related bacteraemia with an antibiotic lock protocol: effect of bacterial pathogen. Nephrol Dial Transplant. 2004;19:1237-44.

46. Popovich RP, Moncrief JW, Decherd JR. The definition of a novel portable/wearable equilibration peritoneal dialysis technique. Trans ASAIO. 1976; 5: 64.

47. Querfeld U. Cardiovascular considerations of pediatric ESRD. In: Warady BA, Schaefer FS, Fine RN, Alexander SR. Pediatric Dialysis. Great Britain: Kluwer Academic Publishers; 2004. p.353-68.

48. Rahim KA, Seidel K, McDonald RA. Risk factors for catheter-related complications in pediatric peritoneal dialysis. Pediatr Nephrol. 2004; 19:1021-8.

49. Russo R, Manili L, Tiraboschi G, Amar K, De Luca M, Alberghini E, Ghiringhelli P, De Vecchi A, Porri MT, Marinangeli G, Rocca R, Paris V, Ballerini L. Patient re-training in peritoneal dialysis: Why and when it is needed. Kidney Int. 2006; 70: S127-32.

50.Sardegna KM, Beck AM, Strife CF. Evaluation of perioperative antibiotics at the time of dialysis catheter placement. Pediatr Nephrol. $1998 ; 12: 149-52$.

51. Schärer K, Fine RN. The history of dialysis therapy in children. In: Warady BA, Schaefer FS, Fine RN, Alexander SR. Pediatric Dialysis. Great Britain: Kluwer Academic Publishers. 2004; p.1-11. 
52. Secker D. Achieving nutritional goals for children on dialysis. In: Warady BA, Schaefer FS, Fine RN, Alexander SR. Pediatric Dialysis. Great Britain: Kluwer Academic Publishers; 2004. p.221-42.

53. Silva MM, Pecoits-Filho R, Rocha CS, Stinghen AE, Pachaly MA, Nascimento MM, et al. The recommendations from the International Society for Peritoneal Dialysis for peritonitis treatment: a single-center historical comparison. Adv Perit Dial. 2004; 20:74-7.

54. Stenvinkel P, Heimburger O, Paultre F, Diczfalusy U, Wang T, Berglund L, Jogestrand T. Strong association between malnutrition, inflammation, and atherosclerosis in chronic renal failure. Kidney Int. $1999 ; 55: 1899-911$.

55. Stone MM, Fonkalsrud EW, Salusky IB, Takiff H, Hall T, Fine RN. Surgical management of peritoneal dialysis catheters in children: fiveyear experience with 1.800 patient-month follow-up. J Pediatr Surg. 1986; 21(12): 1177-81.

56. Strippoli GF, Tong A, Johnson D, Schena FP, Craig JC. Antimicrobial agents to prevent peritonitis in peritoneal dialysis: a systematic review of randomized controlled trials. Am J Kidney Dis. 2004; 44:591-603.

57. Sylvestre LC, Fonseca KPD, Stinghen AEM, Pereira AM, Meneses RP, Pecoits-Filho R. The malnutrition and inflammation axis in pediatric patients with chronic kidney disease. Pediatr Nephrol. 2007; 22:864-73. 
58. Thodis E, Passadakis P, Vargemezis V, Oreopoulos DG. Prevention of catheter-related infections in patients on CAPD. Int $J$ Artif Organs. $2001 ; 24: 671-82$.

59. USRDS - United States Renal Data System. Available from: http:// www.usrds.org.

60. Vas SI, Oreopoulos DG. Infections in patients undergoing peritoneal dialysis. Infect Dis Clin N Am. 2001; 15: 743-74.

61. Vas SI. Peritonitis in peritoneal dialysis patients. In: Nissenson AR, Fine RN. Dialysis therapy. 3a ed. Philadelphia: Hanley \& Belfus; 2002. p. 245-51.

62. Verrina E, Edefonti A, Gianoglio, B, Rinaldi S, Sorino P, Zacchello G, Lavoratti G, Maringhini S, Pecoraro C, Calevo MG, Dertenois LT, Perfumo F. A multicenter experience on patient and technique survival in children on chronic dialysis. Pediatr Nephrol. 2004; 19:82-90.

63.von Lilien T, Gilli G, Salusky IB. Growth in children undergoing continuous ambulatory or cycling peritoneal dialysis. In: Schärer K. Pediatric and Adolescent Endocrinology. Basel: Karger; 1989. p. 2735.

64. von Lilien T, Salusky IB, Yap HK, Fonkalsrud EW, Fine RN. Hernias: a frequent complication in children treated with continuous peritoneal dialysis. Am J Kidney Dis. 1987; 10(5): 356-60.

65. Warady BA, Bohl V, Alon U, Hellerstein S. Symptomatic peritoneal calcification in a child: treatment with tidal peritoneal dialysis. Perit Dial Int. 1994; 14(1): 26-9. 
66. Warady BA, Feneberg R, Verrina E, Flynn JT, Müller-Wiefel DE, Besbas N, Zurowska A, et al. for the International Pediatric Peritonitis Registry (IPPR). Peritonitis in children who receive long-term peritoneal dialysis: a prospective evaluation of therapeutic guidelines. J Am Soc Nephrol. 2007;18(7):2172-9.

67. Warady BA, Schaefer F, Holloway M, Alexander S, Kandert M, Piraino B, Salusky I, Tranaeus A, Divino J, Honda M, Mujais S, Verrina E, International society for peritoneal dialysis (ISPD). Advisory Committee on Peritonitis Management in Pediatric Patients. Consensus guidelines for the treatment of peritonitis in pediatric patients receiving peritoneal dialysis. Perit Dial Int. 2000; 20:610- 24.

68. Warady W, Schaefer FS. Peritonitis. In: Warady BA, Schaefer FS, Fine RN, Alexander SR. Pediatric Dialysis. Great Britain: Kluwer Academic Publishers; 2004. p.393-414.

69. Wolfe RA, Ashby VB, Milford EL, Ojo AO, Ettenger RE, Agodoa LY, Held PJ, Port FK. Comparison of mortality in all patients on dialysis, patients on dialysis awaiting transplantation and recipients of a first cadaveric transplant. N Eng J Med. 1999; 341(23): 1725-30.

70.Wong CS, Hingorani S, Gillen DL, Sherrard DJ, Watkins SL, Brandt JR, Ball A, Stehman-Breen CO. Hypoalbuminemia and risk of death in pediatric patients with end-stage renal disease. Kidney Int. 2002; 61(2): 630-7. 
71. Young GA, Kopple JD, Lindholm B et al. Nutritional assessment of continuous ambulatory peritoneal dialysis patients: an international study. Am J Kidney Dis. 1991; 17:462-71. 